\title{
Contribution of TRPM8 Channels to Cold Transduction in Primary Sensory Neurons and Peripheral Nerve Terminals
}

\author{
Rodolfo Madrid, Tansy Donovan-Rodríguez, Victor Meseguer, Mari Carmen Acosta, Carlos Belmonte, and Félix Viana \\ Instituto de Neurociencias de Alicante, Universidad Miguel Hernández-Consejo Superior de Investigaciones Científicas, 03550 San Juan de Alicante, Spain
}

Transient receptor potential melastatin 8 (TRPM8) is the best molecular candidate for innocuous cold detection by peripheral thermoreceptor terminals. To dissect out the contribution of this cold- and menthol-gated, nonselective cation channel to cold transduction, we identified BCTC [ $N$-(4-tert-butylphenyl)-4-(3-chloropyridin-2-yl)piperazine-1-carboxamide] as a potent and full blocker of recombinant TRPM8 channels. In cold-sensitive trigeminal ganglion neurons of mice and guinea pig, responses to menthol were abolished by BCTC. In contrast, the effect of BCTC on cold-evoked responses was variable but showed a good correlation with the presence or lack of menthol sensitivity in the same neuron, suggesting a specific blocking action of BCTC on TRPM8 channels. The biophysical properties of native cold-gated currents $\left(I_{\text {cold }}\right)$, and the currents blocked by BCTC were nearly identical, consistent with a role of this channel in cold sensing at the soma. The temperature activation threshold of native TRPM8 channels was significantly warmer than those reported in previous expression studies. The effect of BCTC on native $I_{\text {cold }}$ was characterized by a dose-dependent shift in the temperature threshold of activation.

The role of TRPM8 in transduction was further investigated in the guinea pig cornea, a peripheral territory densely innervated with cold thermoreceptors. All cold-sensitive terminals were activated by menthol, suggesting the functional expression of TRPM8 channels in their membrane. However, the spontaneous activity and firing pattern characteristic of cold thermoreceptors was totally immune to TRPM8 channel blockade with BCTC or SKF96365 (1-[2-(4-methoxyphenyl)-2-[3-(4-methoxyphenyl)propoxy]ethyl-1 H-imidazole hydrochloride). Cold-evoked responses in corneal terminals were also essentially unaffected by these drugs, whereas responses to menthol were completely abolished. The minor impairment in the ability to transduce cold stimuli by peripheral corneal thermoreceptors during TRPM8 blockade unveils an overlapping functional role for various thermosensitive mechanisms in these nerve terminals.

Key words: somatosensory; trigeminal ganglion; nociceptor; cornea; BCTC; SKF96365

\section{Introduction}

The activation by low temperatures of specific receptors located on the surface of the body gives rise to a rich spectrum of sensations that range from pleasantly cool to outright painful (Yarnitsky and Ochoa, 1991; Chen et al., 1996; Craig et al., 2000; Acosta et al., 2001). The transduction of temperature stimuli into propagated nerve impulses occurs in free endings of thin sensory axons (Hensel and Zotterman, 1951; Hensel, 1981; Heppelmann et al., 1990). At normal skin temperatures, innocuous cold thermoreceptors exhibit spontaneous, periodic activity that is augmented by cooling and silenced by warming (Hensel and Zotter-

\footnotetext{
Received Feb. 22, 2006; revised 0ct. 24, 2006; accepted 0ct. 24, 2006.

This work was supported by Spanish Ministry of Education and Science Projects SAF2004-01011 (F.V.) and BFU2005-08741 (C.B.). R.M. is a postdoctoral fellow of the Spanish Fundación Carolina, T.D.-R. is a fellow of the Fundación Marcelino Botín, and V.M. holds a predoctoral fellowship from the Generalitat Valenciana. We thank E. Quintero and A. Pérez Vegara for excellent technical assistance. Elvira de la Peña performed the experiments shown in supplemental Figure $3 A$ (available at www.jneurosci.org as supplemental material), and Carolina Luna contributed preliminary data on SKF96365 effects in corneal terminals. The rat TRPM8 and the mouse TRPA1 CDNA were a generous gift from David Julius and Ardem Patapoutian, respectively. We thank Elvira de la Peña, Annika Mälkiä, Patricio Orio, María Dominguez, and Roberto Gallego for comments on this manuscript.

Correspondence should be addressed to Dr. Félix Viana, Instituto de Neurociencias de Alicante, Universidad Miguel Hernández-Consejo Superior de Investigaciones Científicas, Apartado 18, 03550 San Juan de Alicante, Spain. E-mail: felix.viana@umh.es.

DOl:10.1523/JNEUROSCI.3752-06.2006

Copyright $\odot 2006$ Society for Neuroscience $\quad$ 0270-6474/06/2612512-14\$15.00/0
}

man, 1951; Brock et al., 2001). In contrast, cold nociceptors are quiescent at rest firing only in response to low temperatures (LaMotte and Thalhammer, 1982; Simone and Kajander, 1997).

The recent identification of several ion channels with marked sensitivity to cooling provides a molecular framework to understand the transduction mechanisms for cold temperatures by sensory endings (for review, see Jordt et al., 2003; Patapoutian et al., 2003; Reid, 2005). So far, transient receptor potential melastatin 8 (TRPM8), a nonselective cation channel of the transient receptor potential superfamily (McKemy et al., 2002; Peier et al., 2002), is the best molecular candidate to explain the transduction of moderate cold. Recombinant TRPM8 channels are activated by low temperatures (threshold of $\sim 25^{\circ} \mathrm{C}$ ) and by exposure to cooling compounds such as menthol. These channels are expressed selectively in a subpopulation of cold-sensitive (CS) primary sensory neurons (McKemy et al., 2002; Peier et al., 2002) with specific electrophysiological properties (Reid et al., 2002; Viana et al., 2002). In these neurons, cooling opens a cation current $\left(I_{\text {cold }}\right)$ with properties consistent with those of TRPM8dependent currents in transfected cells (Okazawa et al., 2002; Reid et al., 2002). The same neurons are also excited by menthol (McKemy et al., 2002; Reid et al., 2002; Viana et al., 2002; Nealen et al., 2003; Thut et al., 2003).

Nonetheless, a significant percentage of CS neurons in culture 
are insensitive to menthol and lack TRPM8 transcripts (Nealen et al., 2003; Babes et al., 2004). Moreover, other studies have revealed that menthol-insensitive channels also contribute to $I_{\text {cold }}$ (Reid and Flonta, 2001; Viana et al., 2002). Additional evidence for TRPM8-independent cold transduction mechanisms has been reported in damaged sensory endings (Cabanes et al., 2003; Roza et al., 2006). Thus, despite significant advances in our understanding of cold thermotransduction (Brauchi et al., 2004; Voets et al., 2004; McKemy, 2005; Reid, 2005), the role of TRPM8 channels in defining the sensory modality, temperature activation threshold, and spontaneous discharge of native cold receptors is not well established.

Recently, the compound BCTC [N-(4-tert-butylphenyl)-4(3-chloropyridin-2-yl)piperazine-1-carboxamide] has been identified as a blocker of menthol-evoked responses in TRPM8 channels (Behrendt et al., 2004; Weil et al., 2005). Here we show that BCTC is also a potent and rather selective blocker of coldactivated responses in TRPM8 channels. Thereafter, we used BCTC to explore the contribution of TRPM8 to cold-evoked electrical activity in the soma and peripheral nerve terminals of trigeminal ganglion (TG) neurons. Peripheral studies were performed in the cornea, a tissue with a dense innervation of cold thermoreceptors (Gallar et al., 1993; Carr et al., 2003). We conclude that, in the soma of the large majority of cultured trigeminal neurons, activation of TRPM8 channels is the major player in establishing cold-evoked responses. In contrast, TRPM8 channels mediate only the response to menthol of peripheral cold thermoreceptors but not their ongoing activity or the increased impulse discharges evoked by cooling, indicating that thermal sensitivity of innocuous cold thermoreceptors is determined by additional ionic mechanisms.

\section{Materials and Methods}

Rat TRPM8 cDNA (a gift from Dr. David Julius, University of California, San Francisco, CA) was subcloned in the bicistronic vector pcINeo/internal ribosomal entry site-green fluorescent protein (GFP), as described previously, and used for transient transfection in HEK293 cells (de la Pena et al., 2005). Mouse ankyrin-repeat TRP subtype 1 (TRPA1) in pCDNA5 (a gift from Dr. Ardem Patapoutian, Scripps Research Institute, La Jolla, CA) was cotransfected with pGreen Lantern-1 GFP (Invitrogen, Carlsbad, CA)at a 1:1 ratio. Transfected cells were identified by their green fluorescence emission during excitation with $470 \mathrm{~nm}$ light.

Culture of HEK293 cells and trigeminal ganglion neurons. HEK293 cells were obtained from The European Collection of Cell Cultures (Salisbury, UK). Cells were cultured in DMEM containing 10\% of fetal bovine serum and plated on $2 \mathrm{~cm}^{2}$ wells at 400,000 cells per well and grown for $18-48 \mathrm{~h}$ before transfection. Cells were transiently transfected with plasmid DNA using Lipofectamine 2000 (Invitrogen): $2 \mu \mathrm{g}$ of DNA and $3 \mu \mathrm{l}$ of Lipofectamine per well. At $0-24 \mathrm{~h}$ after transfection, cells were trypsinized and replated on laminin-coated round coverslips $(6 \mathrm{~mm}$ diameter) at 30,000 cells per coverslip. At $24-48 \mathrm{~h}$ after transfection, GFPpositive $\left(\mathrm{GFP}^{+}\right)$cells were selected for intracellular calcium measurements and electrophysiological recordings.

Trigeminal ganglion neurons from neonatal mice were cultured as described previously (Viana et al., 2001). In brief, trigeminal ganglia were isolated from anesthetized newborn Swiss OF1 mice [postnatal days 1 (P1) to P5], incubated with $1 \mathrm{mg} / \mathrm{ml}$ collagenase type IA (Sigma, St. Louis, $\mathrm{MO}$ ) for $45 \mathrm{~min}$ at $37^{\circ} \mathrm{C}$ in $5 \% \mathrm{CO}_{2}$, and cultured in medium: $45 \%$ DMEM, $45 \% \mathrm{~F}-12$, and 10\% fetal bovine serum (Invitrogen), supplemented with $4 \mathrm{~mm}$ L-glutamine (Invitrogen), $200 \mu \mathrm{g} / \mathrm{ml}$ streptomycin, $125 \mu \mathrm{g} / \mathrm{ml}$ penicillin, $17 \mathrm{~mm}$ glucose, and nerve growth factor (NGF) (mouse 7S, $100 \mathrm{ng} / \mathrm{ml}$; Sigma). Cells were plated on poly-L-lysine-coated glass coverslips and used after $1-3 \mathrm{~d}$ in culture.

To culture trigeminal ganglion neurons from young adult mice (P25P28) and neonatal (P5-P10) guinea pigs (Hartley strain), the protocol was similar to the one used for neonatal mice except in the following details. Before dissection, mice were anesthetized with $100 \% \mathrm{CO}_{2}$ and guinea pigs with sodium pentobarbital $(90 \mathrm{mg} / \mathrm{kg})$ intraperitoneally, followed by rapid decapitation. After removal, ganglia were incubated in a mixture of collagenase type XI $(0.66 \mathrm{mg} / \mathrm{ml})$ and dispase $(3 \mathrm{mg} / \mathrm{ml})$ for $1 \mathrm{~h}$. After mechanical dissociation, cells were cultured in media containing $89 \%$ MEM and $10 \%$ fetal bovine serum (Invitrogen), supplemented with $1 \%$ MEM vitamins (Invitrogen), $100 \mu \mathrm{g} / \mathrm{ml}$ penicillin/streptomycin, and NGF.

Trigeminal ganglion neurons and HEK293 electrophysiology. Cellattached and whole-cell voltage/or current recordings were performed simultaneously with temperature recordings. The standard bath solution contained the following (in mM): $140 \mathrm{NaCl}, 3 \mathrm{KCl}, 1.3 \mathrm{MgCl}_{2}, 2.4 \mathrm{CaCl}_{2}$, 10 HEPES, and 10 glucose, pH 7.4 adjusted with $\mathrm{NaOH}(297 \mathrm{mOsm} / \mathrm{kg})$. Standard patch pipettes (3-5 M $\Omega$ for HEK293 cells; 5-8 M $\Omega$ for wholecell recordings in neurons; $10-12 \mathrm{M} \Omega$ for cell-attach recordings) were fabricated from borosilicate glass capillaries (Harvard Apparatus, Edenbridge, Kent, UK) and contained the following (in $\mathrm{mM}$ ): for TG neurons, $140 \mathrm{KCl}, 6 \mathrm{NaCl}$, 1 EGTA, $0.6 \mathrm{MgCl}_{2}$, $1 \mathrm{NaATP}, 0.1 \mathrm{Na}-\mathrm{GTP}$, and 10 HEPES, pH 7.4 adjusted with $\mathrm{KOH}(282 \mathrm{mOsm} / \mathrm{kg})$; and for HEK293 cells, $140 \mathrm{CsCl}, 0.6 \mathrm{MgCl}_{2}, 1$ EGTA, and 10 HEPES, pH 7.4, adjusted with $\mathrm{CsOH}(276 \mathrm{mOsm} / \mathrm{kg})$.

To measure the reversal potential of the cold-sensitive current $\left(I_{\text {cold }}\right)$ in sensory neurons, the bath solution contained the following (in $\mathrm{mM}$ ): $140 \mathrm{NaCl}, 3 \mathrm{KCl}, 1.3 \mathrm{MgCl}_{2}, 0.1 \mathrm{CaCl}_{2}, 10 \mathrm{HEPES}, 10$ glucose, and $0.5 \times$ $10^{-3}$ TTX, pH 7.4 adjusted with $\mathrm{NaOH}$. The pipette solution contained the following (in mM): $140 \mathrm{CsCl}, 0.6 \mathrm{MgCl}_{2}, 1$ EGTA, 10 HEPES, 1 $\mathrm{ATPNa}_{2}$, and 0.1 GTPNa, pH 7.4 adjusted with $\mathrm{CsOH}$. These modifications were necessary to minimize large voltage-dependent currents.

Current and voltage signals were recorded with an Axopatch 200B or a Multiclamp patch-clamp amplifier (Molecular Devices, Sunnyvale, CA). Stimulus delivery and data acquisition were performed using pClamp 9 software (Molecular Devices). Analysis was performed with pClamp 9 and WinASCD software (Guy Droogmans, Katholieke Universiteit Leuven, Leuven, Belgium).

Temperature stimulation. Coverslips with cultured cells were placed in a microchamber and continuously perfused $(\sim 0.8 \mathrm{ml} / \mathrm{min})$ with solutions warmed at $34 \pm 1^{\circ} \mathrm{C}$. The temperature was adjusted with a watercooled RDTC-1 Peltier device (ReidDan Electronics) placed directly on the cell field and controlled by a feedback device (Reid et al., 2001). Cold sensitivity was investigated with a $50 \mathrm{~s}$ temperature drop to $18 \pm 1^{\circ} \mathrm{C}$. Temperature decreased and recovered in a quasi-exponential manner with a time constant of $\sim 8 \mathrm{~s}$.

Fluorescence $\mathrm{Ca}^{2+}$ imaging. Neurons were incubated with $5 \mu \mathrm{M}$ fura-2 AM dissolved in standard extracellular solution and $0.02 \%$ pluronic (both from Invitrogen) for $40 \mathrm{~min}$ at $37^{\circ} \mathrm{C}$ in darkness. Fluorescence measurements were made with a Leica (Nussloch, Germany) DM IRE2 inverted microscope fitted with a 12-bit cooled CCD camera (Imago QE Sensicam; T.I.L.L. Photonics, Graefelfing, Germany). Fura-2 was excited at 340 and $380 \mathrm{~nm}$ with a Polychrome IV monochromator (T.I.L.L. Photonics), and the emitted fluorescence was filtered with a $510 \mathrm{~nm}$ long-pass filter. Calibrated ratios $(0.5 \mathrm{~Hz})$ were displayed on-line with T.I.L.L. Vision software version 4.01 (T.I.L.L. Photonics). Bath temperature was sampled simultaneously (see below), and threshold temperature values for $\left[\mathrm{Ca}^{2+}\right]_{\mathrm{i}}$ elevation were estimated by linearly interpolating the temperature at the midpoint between the last baseline point and the first point at which a rise in $\left[\mathrm{Ca}^{2+}\right]_{\mathrm{i}}$ deviated by at least four times the SD of the baseline

Cold nerve terminals electrophysiology. The action of BCTC on coldand menthol-evoked nerve impulse activity was tested on single nerve terminals of cold thermoreceptors innervating the cornea of the eye in an in vitro preparation adapted following Brock et al. (1998). A total of 32 terminals were recorded from the surface of the cornea, five of which were used for the menthol dose-response study, 17 for BCTC experiments, and 10 for investigating SKF96365 effects. Male Dunkin Hartley guinea pigs (Harlan, Borchen, Germany) weighing 250-400 g were anesthetized with sodium pentobarbitone $(20 \mathrm{mg} / \mathrm{kg}$; Dolethal) and killed by decapitation. Corneas were cut at the limbus and pinned to the Sylgardcoated (Dow Corning, Midland, MI) base of a recording chamber, which was superfused continuously with physiological solution of the following 
composition (in mM): $133.4 \mathrm{NaCl}, 1.3 \mathrm{NaH}_{2} \mathrm{PO}_{4}, 16.3 \mathrm{NaHCO}_{3}, 4.7 \mathrm{KCl}$, $2 \mathrm{CaCl}_{2}, 1.2 \mathrm{MgCl}_{2}$, and 9.8 glucose. This solution was gassed with carbogen $\left(95 \% \mathrm{O}_{2}, 5 \% \mathrm{CO}_{2}\right)$ to $\mathrm{pH} 7.4$ and maintained at $34-36^{\circ} \mathrm{C}$.

Glass micropipette electrodes (tip diameter of $\sim 20 \mu \mathrm{m}$ ), filled with the physiological solution and applied to the cornea with light suction, were used to record nerve terminal impulses (NTIs). Electrical signals were recorded with respect to an $\mathrm{Ag} / \mathrm{AgCl}$ pellet placed in the chamber. The electrical activity was recorded through an alternate current amplifier (gain 2000×, highpass filter $0.1 \mathrm{~Hz}$; Neurolog NL103; Digitimer, Welwyn Garden City, UK). Data were captured and analyzed using a CED 1401 interface coupled to a computer running Spike 2 software (Cambridge Electronics Design, Cambridge, UK). Only NTIs originating from single cold-sensitive receptors were recorded, identifiable by their relatively high level of spontaneous discharge (in this study, 4-15 Hz), sometimes in a bursting pattern, which was increased by cooling and decreased by warming of the superfusion solution (Brock et al., 1998, 2001).

Spontaneous NTI activity at $34-36^{\circ} \mathrm{C}$ was recorded for at least $1 \mathrm{~min}$ before cooling the cornea to $22-25^{\circ} \mathrm{C}$ by perfusing it with cold solution during $30 \mathrm{~s}$, followed by rewarming to the baseline temperature of $34-$ $36^{\circ} \mathrm{C}$. Basal mean spontaneous activity (in hertz) was calculated during the $20 \mathrm{~s}$ before cooling. Temperature response threshold was taken as the temperature at which firing frequency increased to a value higher than 2 SDs above the mean basal spontaneous activity, and maximum response was defined as the highest firing frequency reached during cooling.

After two stable, consecutive cooling-rewarming cycles (defined by $<10 \%$ variation in spontaneous activity, threshold, and maximum response between trials), $10 \mu \mathrm{M}$ BCTC was added to the bath solution and allowed to perfuse for $3 \mathrm{~min}$; then, a new cooling-rewarming cycle was applied. The process was repeated in the presence of BCTC and menthol, 10 and $100 \mu \mathrm{M}$, respectively, and finally, with $100 \mu \mathrm{M}$ menthol alone. The dose-response curve of menthol effects on background activity was obtained in five additional corneas that were not exposed to BCTC.

Animal experiments were approved by the local veterinarian authority and were in accordance with the European Union legislation on the use of experimental animals.

Data analysis. To compare the effects of BCTC on cold- or mentholevoked currents in individual cells, data were normalized to percentage of control using the following equation: Relative block (\%) = $\left(\left(\{\text { Response }\}_{\text {control }}-\{\text { Response }\}_{\text {blocker }}\right) /\{\text { Response }\}_{\text {control }}\right) \times 100$. Smooth curves shown in the dose-response relationships are fits to the Hill equation: Relative block $(\mathrm{RB})(\%)=\mathrm{RB}_{\text {min }}+\left(\mathrm{RB}_{\max }-\mathrm{RB}_{\min }\right) /$ $\left.\left[1+\left(\mathrm{X} / \mathrm{EC}_{50}\right)\right)^{N}\right]$, where $\mathrm{EC}_{50}$ is the concentration of half-maximal blockage, $X$ is the blocker concentration, and $N$ is the Hill coefficient.

Unless noted, all dose-response curves of current block were measured at $+80 \mathrm{mV}$. For estimates of BCTC block during cooling, leak currents were measured at $35^{\circ} \mathrm{C}$, thus minimizing TRPM 8 activation, and temperature-corrected by a factor $Q_{\Delta \mathrm{T}}$ according to the following expression: $Q_{\Delta \mathrm{T}}=\left(Q_{10}\right) \times \exp (\Delta \mathrm{T} / 10)$, where $\Delta \mathrm{T}$ is the difference between the baseline temperature $\left(35^{\circ} \mathrm{C}\right)$ and the temperature of the cold stimulus. The value of $Q_{10}$ was fixed at 1.5, a reasonable value for "coldinsensitive" (CI) channels (Hille, 2001).

Data are presented as means \pm SEM. Statistical analyses were performed with Excel 2001 (Microsoft, Seattle, WA) or SigmaStat 3.0 software (Systat Software, Port Richmond, CA). Significance was set at $p<$ 0.05 .

Reagents. BCTC was a generous gift from Dr. H. Behrendt and Dr. R. Jostock (Grünenthal AG, Aachen, Germany). L-Menthol was purchased from Scharlau Chemie (Barcelona, Spain). Cinnamon aldehyde, clotrimazole [(1-(o-chloro- $\alpha, \alpha$-diphenylbenzyl)-imidazole)], phenanthroline (1-10-phenanthroline monohydrate), 4-aminopyridine, and nickel chloride were from Sigma. SKF96365 (1-[2-(4-methoxyphenyl)-2-[3-(4methoxyphenyl)propoxy] ethyl- $1 \mathrm{H}$-imidazole hydrochloride] was purchased from Tocris Bioscience (Bristol, UK).

\section{Results \\ BCTC blocks $\left[\mathrm{Ca}^{2+}\right]_{\mathrm{i}}$ responses to cold and menthol in TRPM8-transfected HEK293 cells}

BCTC is a novel blocking agent of transient receptor potential vanilloid receptor 1 (TRPV1) channels (Valenzano et al., 2003) and of mouse and human TRPM8 channels activated by menthol (Behrendt et al., 2004; Weil et al., 2005). Using fura-2 calcium imaging in rat TRPM8-transfected HEK293 cells, we confirmed the blocking effects of BCTC on menthol-evoked responses. As shown in Figure 1A, BCTC produced a reversible suppression of $\left[\mathrm{Ca}^{2+}\right]_{i}$ elevations to menthol application. In nontransfected cells, menthol had no effect on $\left[\mathrm{Ca}^{2+}\right]_{\mathrm{i}}$ levels. At $3 \mu \mathrm{M}$ BCTC, the inhibition was complete, with an $\mathrm{EC}_{50}$ value of $647 \mathrm{~nm}$ (Fig. $1 D$ ). Next, we tested the effects of BCTC on cold-evoked calcium signals in TRPM8-transfected HEK293 cells. As was the case for menthol responses, BCTC produced a dose-dependent and reversible inhibition of $\left[\mathrm{Ca}^{2+}\right]_{\mathrm{i}}$ elevations evoked by cooling down to $\sim 18^{\circ} \mathrm{C}$ from a baseline temperature of $35^{\circ} \mathrm{C}$ (Fig. $1 \mathrm{E}$ ). Inhibition was also complete at $3 \mu \mathrm{m}$ with an $\mathrm{EC}_{50}$ of $685 \mathrm{~nm}($ Fig. $1 \mathrm{H})$.

\section{BCTC blocks currents evoked by menthol and cold in TRPM8-transfected HEK293 cells}

The blockade of TRPM8 channels by BCTC was verified directly, testing its effect on menthol-evoked whole-cell currents $\left(I_{\text {men }}\right.$ thol). Current development was monitored with periodic injections of voltage ramps from -100 to $+100 \mathrm{mV}$. Application of $100 \mu \mathrm{M}$ menthol at $33-34^{\circ} \mathrm{C}$ activated a current characterized by a reversal potential near $0 \mathrm{mV}(-3.5 \pm 0.7 \mathrm{mV} ; n=21)$ and strong outward rectification $\left(I_{+80 \mathrm{mV}} / I_{-80 \mathrm{mV}}\right.$ of $110 \pm 32 ; n=$ 21) (Fig. 1C). As shown in Figure $1, B$ and $C, 3 \mu \mathrm{M}$ BCTC produced a complete inhibition of menthol-gated TRPM8 currents that recovered to a large extent during wash. The time constant of current inhibition by $3 \mu \mathrm{M}$ BCTC was $6.7 \pm 1.1 \mathrm{~s}(n=4)$. The full dose-response curve of BCTC blockade of $I_{\text {menthol }}$ is shown in Figure $1 D$, with an estimated $\mathrm{EC}_{50}$ of $475 \mathrm{~nm}$.

The actions of BCTC on cold-evoked currents $\left(I_{\text {cold }}\right)$ were also tested in whole-cell recordings of TRPM8-transfected HEK293 cells, using identical protocols. From a baseline temperature of $33-35^{\circ} \mathrm{C}$, cooling to $\sim 18^{\circ} \mathrm{C}$ activated a current (Fig. $1 G$ ) with similar outward rectification $\left(I_{+80 \mathrm{mV}} / I_{-80 \mathrm{mV}}\right.$ of $103 \pm 27 ; n=$ 23) and reversal potential of $-1.5 \pm 0.9 \mathrm{mV}(n=24)$ as after applying menthol. BCTC produced a dose-dependent reduction in the current that reversed rapidly during wash (Fig. $1 F, G$ ). At 3 $\mu \mathrm{M}$, the inhibition was complete and the time constant of inhibition was $11.0 \pm 1.6 \mathrm{~s}(n=8)$. A full dose-response curve of BCTC effects on cold-evoked currents is shown in Figure $1 H$. In this case, the estimated $\mathrm{EC}_{50}$ was $621 \mathrm{nM}$, similar to the values obtained for $I_{\text {menthol }}$. The inhibition of $I_{\text {menthol }}$ and $I_{\text {cold }}$ by BCTC appeared to be voltage dependent: inward currents were fully blocked at negative potentials by submaximal concentrations of BCTC, but a fraction of current remained at more positive potentials (Fig. $1 G$ ). The voltage dependence of block was quantified, comparing the block produced by $1 \mu \mathrm{M}$ BCTC at +40 and $+100 \mathrm{mV}$. In the case of $I_{\text {menthol }}$, mean percentage of block was $88.5 \pm 4.5$ and $64.5 \pm 5.7 \%$ at +40 and $+100 \mathrm{mV}$, respectively $(p=0.01 ; n=5)$. For $I_{\text {cold }}$, the values of block produced by $1 \mu \mathrm{M}$ BCTC were similar to those of $I_{\text {menthol }}(82.4 \pm 3.8$ and $64.3 \pm$ $5.4 \%)$ and also significantly different at both potentials $(p=$ $0.04 ; n=4)$.

We also tested the effects of several other known blockers of TRP channels, such as clotrimazole, phenanthroline, and SKF96365 (Nilius et al., 2001; Hill et al., 2004), and nickel, a blocker of voltage-gated calcium channels. With the exception of nickel, which at concentrations as high as $10 \mathrm{~mm}$ was almost inactive against cold-evoked currents, the rest of the compounds also exhibited strong inhibitory effects on TRPM8 channels (R. Madrid, V. Meseguer, and F. Viana, unpublished observations). BCTC and SKF96365 were the two most potent compounds 

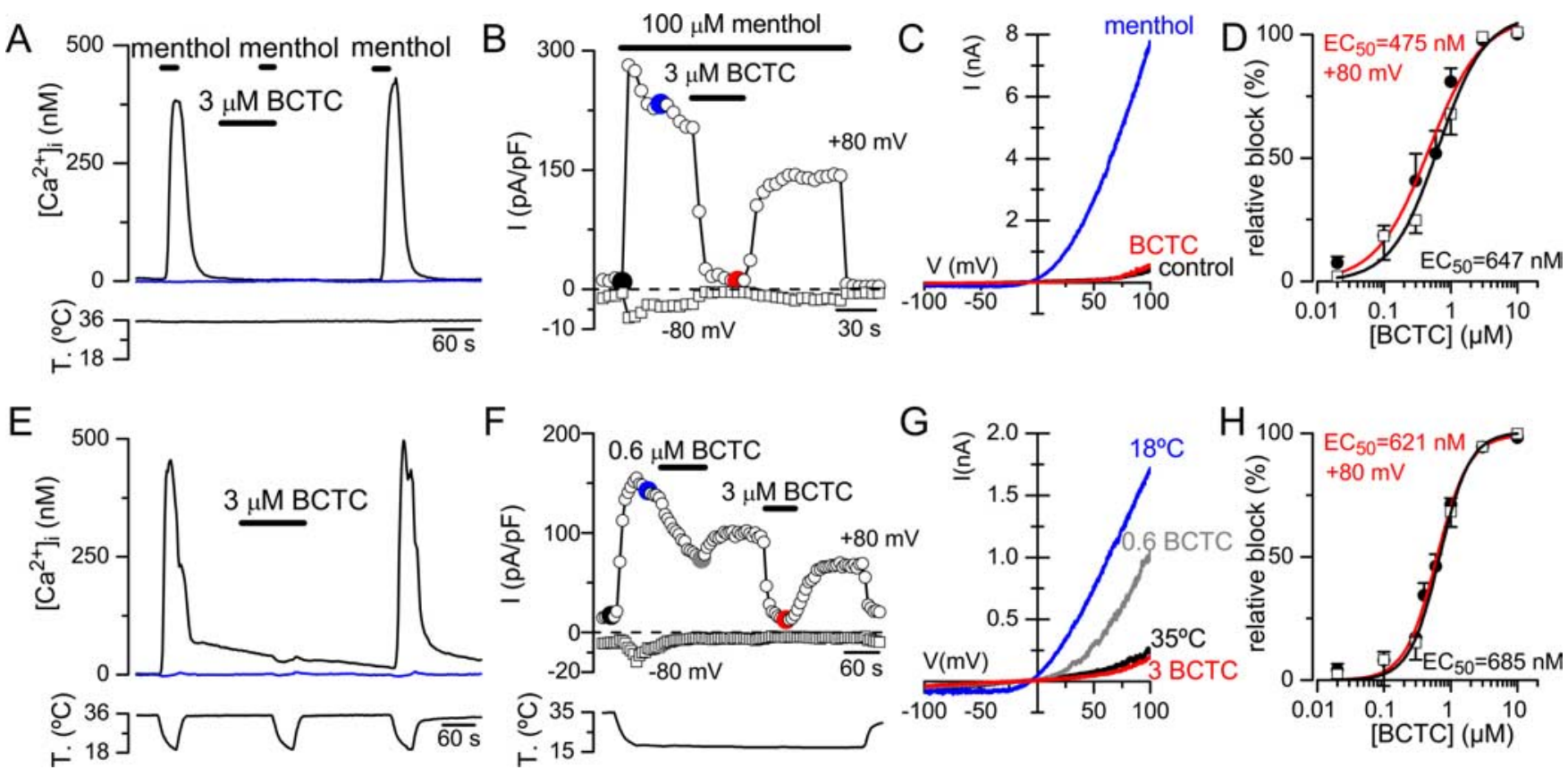

Figure 1. BCTC blocks TRPM8-mediated responses to cold and menthol in transfected HEK293 cells. A, Ratiometric $\left[\mathrm{Ca}^{2+}{ }^{2+}\right]_{\mathrm{i}}$ response of a TRPM8 ${ }^{+}$HEK293 cell (black trace) to $100 \mu \mathrm{m}$ menthol in control solution, in the presence of $3 \mu \mathrm{MBCTC}$, and after washout of BCTC. In the same field, a TRPM8-negative (TRPM8 ${ }^{-}$) cell (blue trace) did not respond to menthol. $\boldsymbol{B}$, Time course of current development at +80 and $-80 \mathrm{mV}$ in a TRPM8 ${ }^{+}$HEK293 cell, recorded at $33^{\circ}$ C, by the application of $100 \mu \mathrm{m}$ menthol. In the continuous presence of menthol, $3 \mu \mathrm{m} \mathrm{BCTC} \mathrm{produced} \mathrm{a} \mathrm{full} \mathrm{suppression}$ of the current. Currents were evoked by a 1-s-duration $-100 /+100 \mathrm{mV}$ voltage ramp delivered every $5 \mathrm{~s}$. The negative current axis is expanded fivefold to show the very small inward currents. $C$, Whole-cell ramp $I-V$ relationship at $33^{\circ} \mathrm{C}$ in control solution (black trace), during $100 \mu \mathrm{m}$ menthol (blue trace), and during $100 \mu \mathrm{m}$ menthol plus $3 \mu \mathrm{m} \mathrm{BCTC} \mathrm{(red} \mathrm{trace).} \mathrm{D,} \mathrm{Relative} \mathrm{block} \mathrm{of} \mathrm{calcium}$ response (open squares) and menthol-evoked currents (filled circles) to cooling pulses as a function of BCTC concentration ( $n=5-10$ cells for calcium data and $2-5$ cells for current data). Solid lines correspond to dose-response fits to the Hill equation, in black for menthol data ( $\mathrm{EC}_{50}$ of $647 \mathrm{~nm}$ and a Hill coefficient of 1.9), and in red for current data ( $\mathrm{EC}_{50}$ of $475 \mathrm{~nm}$ and Hill coefficient of 1.1$)$. $\boldsymbol{E}$, Ratiometric $\left[\mathrm{Ca}^{2+}\right]_{\mathrm{i}}$ response in a TRPM8 ${ }^{+}$HEK293 cell (same as in $A$ ) during a cooling stimulus in control solution and in the presence of $3 \mu \mathrm{mBCTC}$. Note the lack of response in a TRPM8 ${ }^{-}$cell (blue trace) recorded simultaneously. $\boldsymbol{F}$, Time course of current at +80 and $-80 \mathrm{mV}$ in a TRPM $8^{+}$HEK293 cell during a cooling stimulus and effect of 0.6 and $3 \mu \mathrm{m}$ BCTC. Same voltage protocol as in $\boldsymbol{B}$. The negative current axis is expanded twofold. G, I-V relationship of currents at $35^{\circ} \mathrm{C}$ (black trace), during cooling at $18^{\circ} \mathrm{C}$ (blue trace), and during cooling in the presence of 0.6 (gray trace) and $3 \mu \mathrm{M}$ BCTC (red trace). $\boldsymbol{H}$, Normalized block of cold-evoked calcium signals (open squares) and currents (filled circles) in TRPM8 ${ }^{+}$HEK293 cells by different concentrations of BCTC. The smooth curves are fits of the Hill equation to the data with an $\mathrm{EC}_{50}$ of $685 \mathrm{~nm}$ and a Hill coefficient of 1.9 for calcium data (black line; $n=5-10$ cells) and an $\mathrm{EC}_{50}$ of $621 \mathrm{~nm}$ and $N=1.8 \mathrm{for}$ current data at $+80 \mathrm{mV}$ (red line; $n=2-8$ cells).

Table 1. Electrophysiological properties of cold-sensitive neurons recorded in control solution and in the presence of $3 \mu \mathrm{M} B C T C$

\begin{tabular}{llllllll}
\hline & $V_{\text {rest }}(\mathrm{mV})$ & $R_{\text {in }}(\mathrm{M} \Omega)$ & $\mathbb{I}_{\text {index }}(\%)$ & $I_{\text {rheobase }}(\mathrm{pA})$ & I-evoked firing $(\mathrm{Hz})$ & AP amplitude $(\mathrm{mV})$ & AP duration $(\mathrm{ms})$ \\
\hline Control & $-49.5 \pm 1.4(n=18)$ & $544 \pm 103(n=8)$ & $28.3 \pm 5.8(n=8)$ & $107 \pm 36(n=10)$ & $77 \pm 18(n=10)$ & $71 \pm 3(n=10)$ & $0.9 \pm 0.1(n=10)$ \\
$3 \mu \mathrm{MBCTC}$ & $-46.6 \pm 1.6(n=18)$ & $573 \pm 129(n=5)$ & $22.1 \pm 5.4(n=5)$ & $89 \pm 30(n=10)$ & $76 \pm 15(n=10)$ & $60 \pm 5(n=10)$ & $0.9 \pm 0.1(n=10)$ \\
$t$ test & $p=0.17$ & $p=0.87$ & $p=0.45$ & $p=0.71$ & $p=0.83$ & $p=0.08$ & $p=0.63$ \\
\hline
\end{tabular}

$V_{\text {rest, }}$ Resting membrane potential; $R_{\text {in, }}$ input resistance; $\left[R_{\text {index, }}\right.$ inward rectification index (percentage), measured as $\left[\left(\left(V_{\mathrm{m} \text { peak }}-V_{\mathrm{m} \text { steady-state }}\right) / V_{\mathrm{m} \text { peak }}\right) \times 100\right]$ during hyperpolarizing voltage responses induced by $-100 \mathrm{pA}(250 \mathrm{~ms})$ current pulses under current clamp from $I_{\text {hold }}$ of $0 \mathrm{pA} ; I_{\text {hheobase, }}$, heobase current; $I$-evoked firing frequency was calculated from the number of AP evoked by a $1 \mathrm{~s}$ depolarizing current ramp of $500 \mathrm{pA}$, in a time interval of $250 \mathrm{~ms}$ from the first spike evoked. AP amplitude was measured from base to pick of the first spike during the depolarizing ramp. AP duration was measured at half-amplitude. $t$ test, Two-tailed Student's $t$ test.

tested and were subsequently used to dissect the functional activity of native TRPM8 channels in cold-sensitive neurons and corneal thermoreceptor terminals.

\section{Identification and properties of cold-sensitive trigeminal ganglion neurons}

Calcium imaging techniques were used for a fast and reliable identification of the subpopulation of CS mouse trigeminal ganglion neurons (McKemy et al., 2002; Viana et al., 2002). During rapid reductions in bath temperature from a baseline temperature of $33-35^{\circ} \mathrm{C}$ to $\sim 18^{\circ} \mathrm{C}$, a small fraction $(\sim 10 \%)$ of neurons responded with an elevation in their $\left[\mathrm{Ca}^{2+}\right]_{\mathrm{i}}$. The average increase in $\left[\mathrm{Ca}^{2+}\right]_{\mathrm{i}}$ produced by cooling was $205 \pm 20 \mathrm{nM}(n=88)$. As reported previously, CS trigeminal neurons had a small round- or ovoid-shaped soma (average diameter of $15.7 \pm 0.3$ $\mu \mathrm{m} ; n=88$ ) and a mean whole-cell capacitance of $10.3 \pm 0.4 \mathrm{pF}$ $(n=42)$. CS neurons had variable temperature thresholds ranging from 35.2 to $21.1^{\circ} \mathrm{C}(n=88)$. Nearly all CS neurons identified in calcium imaging screens were also activated by menthol (94.9\% of all neonatal CS tested; $n=59$ ). Furthermore, in CS neurons, we observed the development of robust inward currents during brief applications of menthol (see below), strongly suggesting a contribution of TRPM8 channels to their depolarizing response during cooling. The membrane properties of these neonatal CS trigeminal neurons are summarized in Table 1.

BCTC markedly reduced cold and menthol $\left[\mathrm{Ca}^{2+}\right]_{\mathrm{i}}$ responses in a large fraction of cultured cold-sensitive trigeminal ganglion neurons

At a concentration of $3 \mu \mathrm{M}, \mathrm{BCTC}$ produced a complete suppression of the $\left[\mathrm{Ca}^{2+}\right]_{\mathrm{i}}$ rise evoked by application of $100 \mu \mathrm{M}$ menthol in neonatal CS trigeminal neurons (Fig. $2 A, B$ ). On its own, BCTC did not modify resting $\left[\mathrm{Ca}^{2+}\right]_{\mathrm{i}}$ levels in CS or CI neurons. The inhibition by BCTC was fully reversible in all neurons tested $(n=12)$ (Fig. $2 B, C)$. This effect of BCTC on menthol-evoked 
responses in the soma of trigeminal sensory neurons is entirely consistent with the actions on expressed TRPM8 channels described above.

In contrast, the effects of the drug on cold-evoked responses varied from neuron to neuron, from full suppression to no effect. This variability is illustrated in Figure $2 D$, which shows the effect of $3 \mu \mathrm{M}$ BCTC on $\left[\mathrm{Ca}^{2+}\right]_{\mathrm{i}}$ responses to cooling in three CS trigeminal neurons recorded simultaneously. In the neuron with the largest initial $\left[\mathrm{Ca}^{2+}\right]_{\mathrm{i}}$ response (blue trace), BCTC produced a complete suppression of the $\left[\mathrm{Ca}^{2+}\right]_{i}$ rise. In the neuron with the smallest initial response (green trace), the inhibition was incomplete, and, in the third cell (red trace), the effect of BCTC was negligible. As shown also in Figure 2D, the effects of BCTC were fully reversible after only a few minutes wash. In $52 \%$ of the neurons with a response to cooling $(n=88)$, the $\left[\mathrm{Ca}^{2+}\right]_{\mathrm{i}}$ rise was fully blocked, in $40 \%$ the inhibition was partial, and in seven cells $(8 \%)$ BCTC had no blocking action. Interestingly, all coldsensitive but BCTC-insensitive TG neurons tested were also menthol unresponsive $(n=3)$ (note the red trace in Fig. $2 D$ ). In contrast, all BCTC-sensitive neurons tested were also activated by menthol $(n=$ 56). These results strongly support the view that BCTC is acting preferentially on TRPM8 channels. The effects of BCTC on cold-evoked responses were dose dependent and are summarized in Figure $2 E$ for the entire population of neonatal CS neurons.

In adult mouse CS trigeminal neurons, the effects of BCTC were very similar to those found in neonates. As shown in supplemental Figure 1 (available at www.jneurosci.org as supplemental material), BCTC also produced a powerful, fully reversible, inhibition of cold- and menthol-evoked $\left[\mathrm{Ca}^{2+}\right]_{\mathrm{i}}$ responses. Of 19 CS neurons tested (all were activated by $100 \mu \mathrm{M}$ menthol), $3 \mu \mathrm{M}$ BCTC fully suppressed menthol-evoked responses in 15 of them (79\%). In contrast, cold-evoked responses were fully blocked in nine neurons (47\%), whereas in the remaining 10 cells the inhibition was only partial, decreasing from $153 \pm 19 \mathrm{~nm}$ in control solution to $86 \pm 9 \mathrm{nM}$ in $3 \mu \mathrm{M}$ BCTC $(p<0.001)$.

\section{BCTC shifted the temperature threshold of cold-sensitive trigeminal ganglion neurons}

To pinpoint the role of TRPM8 channels in CS trigeminal neurons during cold sensing, we performed simultaneous recordings of $\left[\mathrm{Ca}^{2+}\right]_{\mathrm{i}}$ signals and electrical activity from their soma (Fig. $3 A$ ) using the cell-attached mode of the patch-clamp technique, a recording configuration that preserves the intracellular milieu of the cell, thus minimizing alterations in modulatory factors. With the use of subsaturating doses of BCTC, we were able to reduce the functional density of active TRPM8 channels in the cell membrane and asked how this reduction affected the threshold temperature for excitation.

As shown in Figure $3 B$, cooling evoked a $\left[\mathrm{Ca}^{2+}\right]_{\mathrm{i}}$ response in parallel with the onset of action potential (AP) firing. In the pres-
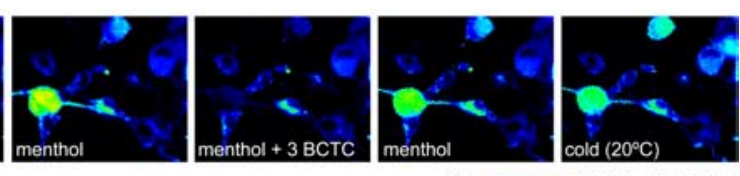

$0=600 \mathrm{nM}\left[\mathrm{Ca}^{2+}\right]$
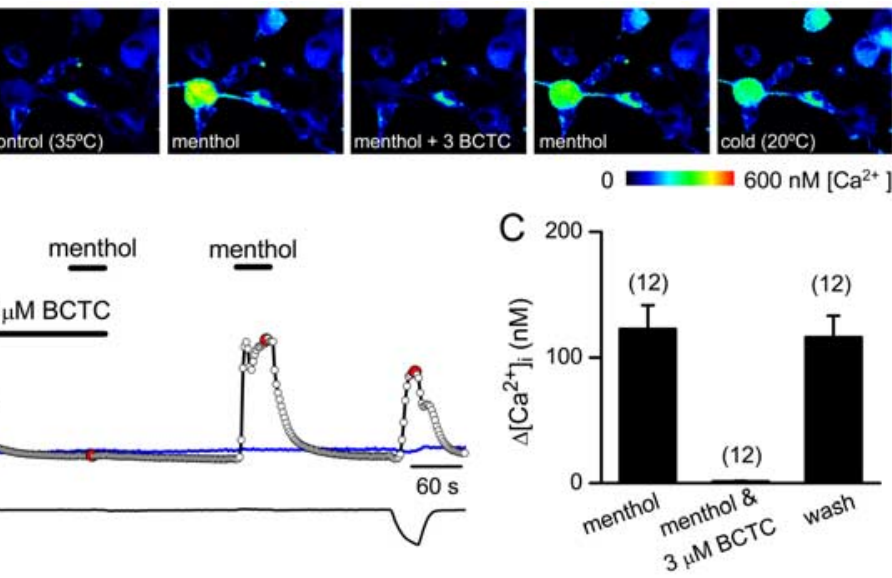

(12)
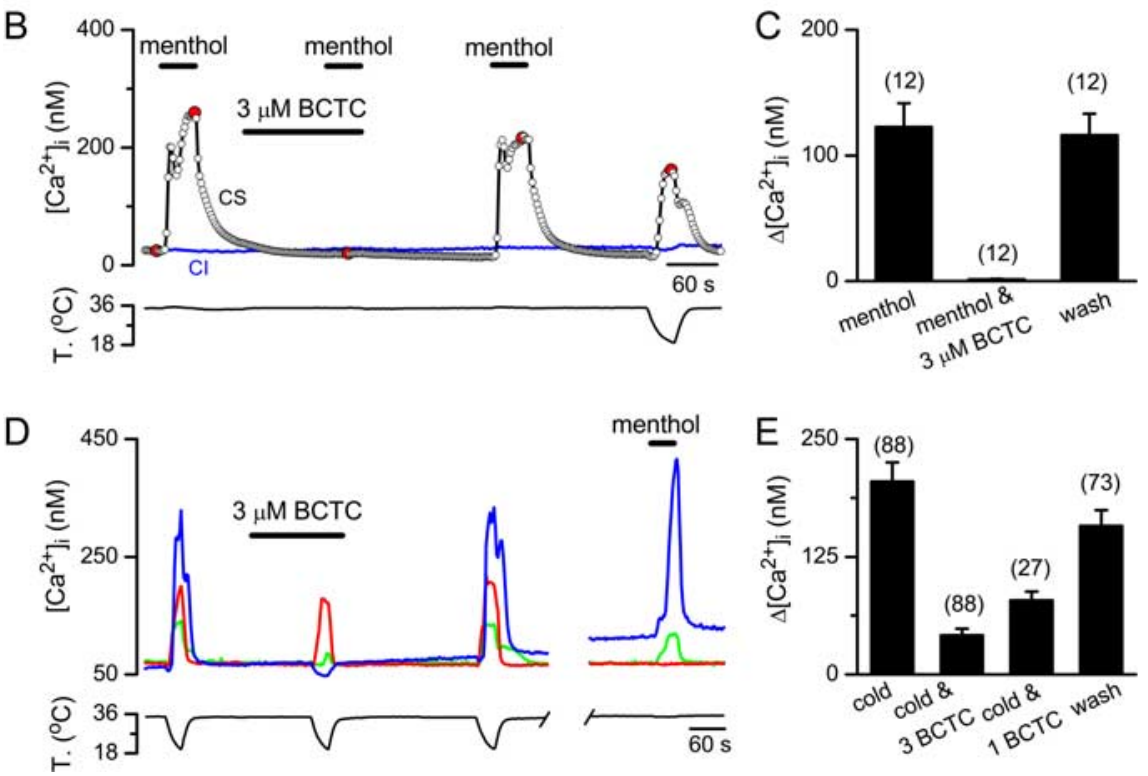

Figure 2. $\quad B C T C$ blocks menthol- and cold-induced $\left[\mathrm{Ca}^{2+}\right]_{i}$ responses in neonatal mice trigeminal sensory neurons. $\boldsymbol{A}$, Trans(left) and pseudocolor ratiometric $\left[\mathrm{Ca}^{2+}\right]_{\mathrm{i}}$ images showing the effects of BCTC on menthol-evoked $\left[\mathrm{Ca}^{2+}\right]_{i}$ signals in cultured trigeminal neurons. The fluorescence images correspond with the time points marked in red in $\boldsymbol{B}$. Scale bar, $15 \mu \mathrm{m}$. $\boldsymbol{B}$ $\mu \mathrm{MBCTC}$, and after washout of BCTC. C, Mean evoked $\left[\mathrm{Ca}^{2+}\right]_{\mathrm{i}}$ elevation by menthol, by menthol in the presence of $3 \mu \mathrm{m}$ BCTC, neurons is also shown. The time gap equals $550 \mathrm{~s}$. $\boldsymbol{E}$, Mean evoked $\left[\mathrm{Ca}^{2+}\right]_{\mathrm{i}}$ elevation by cooling in control solution, in the presence of 1 and $3 \mu \mathrm{M} B C T C$, and after wash in mouse CS trigeminal neurons.

ence of $1 \mu \mathrm{M}$ BCTC, the reduction in the amplitude of the $\left[\mathrm{Ca}^{2+}\right]_{\mathrm{i}}$ signal correlated with reduced impulse firing and was accompanied by a shift in threshold to lower temperatures: in this particular neuron, the firing threshold shifted from $33.7^{\circ} \mathrm{C}$ in control conditions to $28.4^{\circ} \mathrm{C}$ in the presence of $1 \mu \mathrm{M}$ BCTC. In $3 \mu \mathrm{M}$ BCTC, the cell fired a single action potential at $20.2^{\circ} \mathrm{C}$ and the $\left[\mathrm{Ca}^{2+}\right]_{\mathrm{i}}$ elevation was completely abolished. The effects of BCTC on cold-evoked firing and $\left[\mathrm{Ca}^{2+}\right]_{\mathrm{i}}$ signals were reverted during wash. As summarized in Figure $3 C$, in neurons recorded in control solution (filled circles), there was a tight correspondence between temperature threshold for firing of action potentials and for $\left[\mathrm{Ca}^{2+}\right]_{\mathrm{i}}$ elevations in each individual cell. The correlation between both thresholds had a slope of 0.98 and an $r$ value of 0.99 $(n=11)$. When repeating this experiment after applying $1 \mu \mathrm{M}$ (triangles) or $3 \mu \mathrm{M}$ (stars) BCTC, this tight correlation was maintained (Fig. $3 C$ ), and the absolute difference in threshold between $\left[\mathrm{Ca}^{2+}\right]_{\mathrm{i}}$ signals and AP firing was only $0.1 \pm 0.14^{\circ} \mathrm{C}$. This result indicates that the onset of $\left[\mathrm{Ca}^{2+}\right]_{\mathrm{i}}$ signals can be used as a reliable marker of electrical activity and of the effects of BCTC on temperature threshold in individual CS neurons.

Figure $4 A$ summarizes the effects of applying 1-3 $\mu \mathrm{M}$ BCTC on cold-evoked activity in the 88 neonatal CS neurons analyzed (see above). In the graph, individual neurons have been plotted according to their initial temperature threshold (black circles). In all but seven cells (8\%) (green circles), $3 \mu \mathrm{M}$ BCTC produced marked increases in temperature threshold (i.e., the temperature for activation decreased). In fact, as already mentioned, in 52\% of 
A
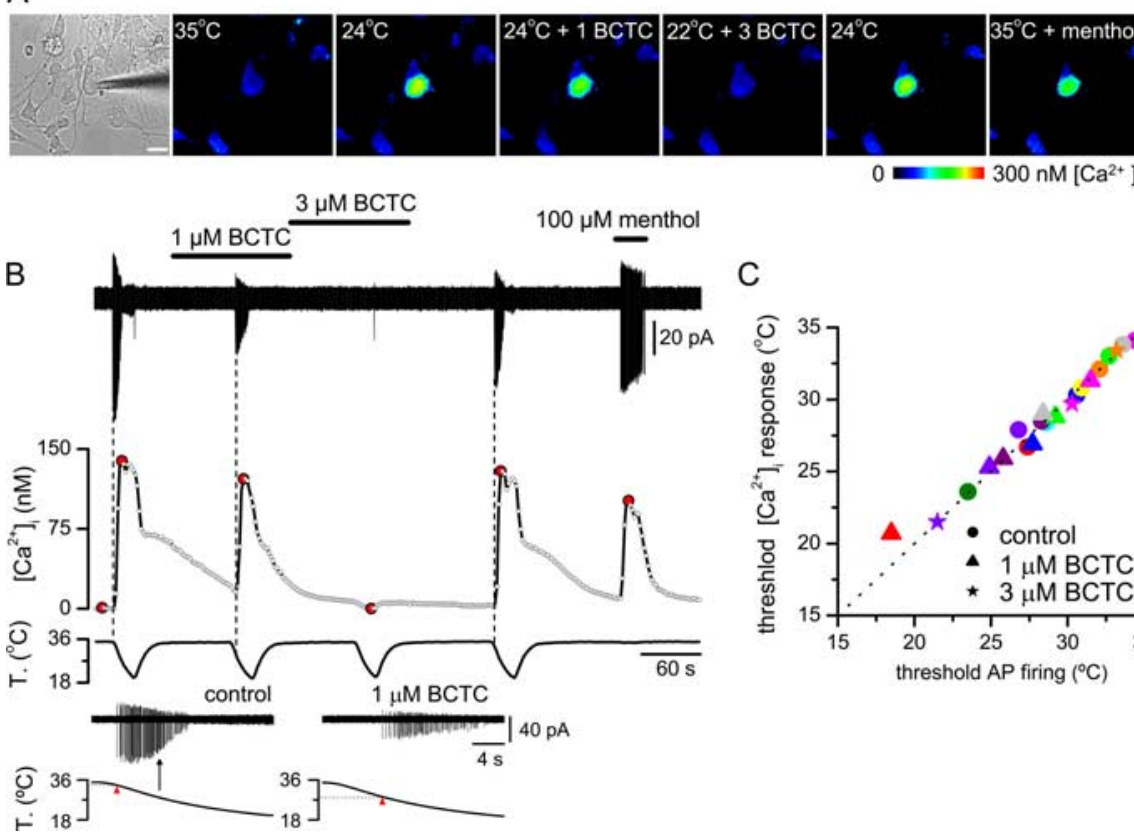

C

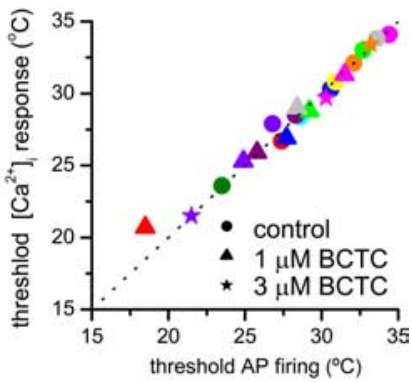

Figure 3. $B C T C$ reduces firing and shifts temperature threshold in cold-sensitive trigeminal ganglion neurons. $A$, Transmitted (left) and pseudocolor ratiometric $\left[\mathrm{Ca}^{2+}\right]_{i}$ images showing the effects of $\mathrm{BCTC}$ on cold-evoked $\left[\mathrm{Ca}^{2+}\right]_{i}$ signals in a CS trigeminal neuron. Note also the response to menthol. A patch pipette has been positioned in close apposition to the $C S$ cell before initiating the sequence of cell-attach recordings. The fluorescence images correspond with the time points marked in red in $\boldsymbol{B}$. $\boldsymbol{B}$, Simultaneous recording of action currents (top trace), $\left[\mathrm{Ca}^{2+}\right]_{i}$ signals (middle), and bath temperature (bottom) during four consecutive cooling ramps. The two insets at the bottom show the action currents and the temperature change on an expanded timescale, in control (left) and $1 \mu \mathrm{M}$ BCTC (right). The temperature threshold is marked by a pink arrowhead. The black arrow marks, on the control trace, the temperature threshold in $1 \mu \mathrm{m}$ BCTC. Note the decline in action current amplitude with low temperature. $C_{\text {, }}$ Scatter plot of thresholds for action potential and $\left[\mathrm{Ca}^{2+}\right]_{i}$ signals in response to cooling in 11 neurons (each neuron has been color coded) recorded in control solution (circles) and $1 \mu \mathrm{m}$ (triangles) and $3 \mu \mathrm{M}$ (stars) BCTC. The dotted line represents the unity line.
A

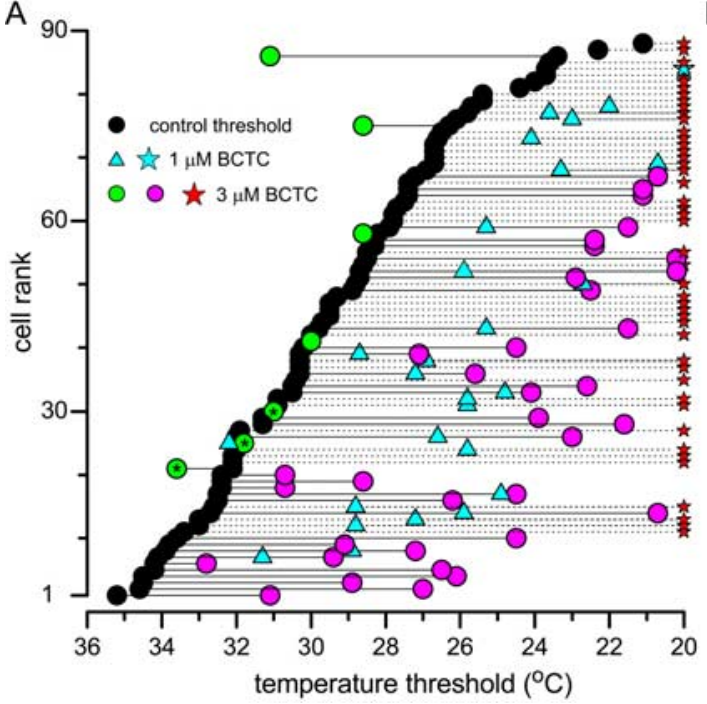

B
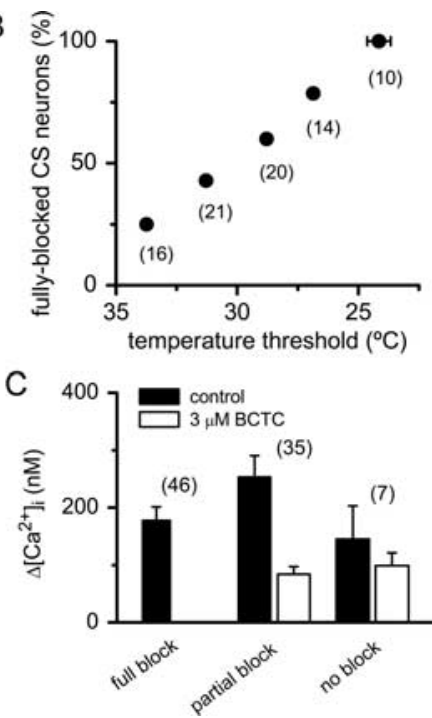

Figure 4. BCTC shifts temperature threshold in mouse cold-sensitive trigeminal ganglion neurons in a dose-dependent manner. $\boldsymbol{A}$, Dot plot summarizing the effect of 1 and $3 \mu \mathrm{m} \mathrm{BCTC}$ on cold-evoked temperature threshold in 88 cold-sensitive TG neurons. Threshold was estimated from the ratiometric $\left[\mathrm{Ca}^{2+}\right]_{\mathrm{i}}$ responses to cooling. The 88 neurons have been plotted according to initial temperature threshold in control solution (black circles) from lowest to highest threshold. The threshold measured in 1 and $3 \mu \mathrm{m}$ $\mathrm{BCTC}$ is represented by cyan triangles and magenta circles, respectively. Those neurons fully inhibited by $3 \mu \mathrm{M}$ BCTC during a cooling ramp to $20-18^{\circ} \mathrm{C}$ are represented by a red star. The green circles mark the threshold in $3 \mu \mathrm{M} \mathrm{BCTC}$ for those neurons whose temperature threshold were not augmented by BCTC: $100 \mu \mathrm{m}$ menthol was tested in three of these neurons (asterisk) and had no effect. $\boldsymbol{B}$, Diagram representing the percentage of CS neurons fully inhibited by $3 \mu \mathrm{m} \mathrm{BCTC}$ of the total population with responses to cooling affected by BCTC $(n=81)$. Neurons have been grouped according to initial temperature threshold. The horizontal error bars in four groups overlap with symbol size. $C$, Bar histogram summarizing the effect of $3 \mu \mathrm{m} \mathrm{BCTC}$ on cold-evoked $\left[\mathrm{Ca}^{2+}\right]_{\mathrm{i}}$ responses in the three subpopulations of neurons grouped according to blocking effect of BCTC. cells, $3 \mu \mathrm{M}$ BCTC completely suppressed the $\left[\mathrm{Ca}^{2+}\right]_{\mathrm{i}}$ response during cooling down to $20-18^{\circ} \mathrm{C}$ (red stars). In neurons showing a partial blockade (40\%), $3 \mu \mathrm{M}$ BCTC shifted the threshold by $6.3 \pm 0.4^{\circ} \mathrm{C}$ toward the colder range (magenta circles). In comparison, $1 \mu \mathrm{M}$ BCTC eliminated the $\left[\mathrm{Ca}^{2+}\right]_{\mathrm{i}}$ elevation induced by cold in just one neuron (cyan star) and shifted the temperature threshold to intermediate values (cyan triangles) with a mean shift of $4.1 \pm 0.3^{\circ} \mathrm{C}(n=27)$. The shift in threshold produced by BCTC was accompanied by a reduction in the amplitude of the $\left[\mathrm{Ca}^{2+}\right]_{\mathrm{i}}$ attributable to a decrease in the firing frequency of action potentials (Fig. $4 C)$. The effects of BCTC on temperature threshold and $\left[\mathrm{Ca}^{2+}\right]_{\mathrm{i}}$ elevation were almost fully reversible (Fig. 3B).

It is noteworthy that BCTC produced these inhibitory effects in CS neurons with widely different initial temperature thresholds, from the innocuous to the noxious range, and including those with very low threshold. As shown in Figure 4B, the high-threshold cells were much more likely to be silenced by $3 \mu \mathrm{M}$ BCTC than low-threshold CS neurons. In contrast, the few BCTC-insensitive neurons (green circles) were not clustered in any particular threshold temperature range. Figure $4 C$ shows the mean $\left[\mathrm{Ca}^{2+}\right]_{\mathrm{i}}$ elevation evoked by cold in trigeminal neurons grouped according to their sensitivity to BCTC. There was a notable variability in the amplitude of cold-evoked $\left[\mathrm{Ca}^{2+}\right]_{\mathrm{i}}$ responses in individual cells, without significant difference between the means of the three groups ( $p=0.16$, Kruskall-Wallis ANOVA).

Altogether, these results indicate that TRPM8 channels are expressed in the soma of a majority of mouse cultured CS trigeminal neurons and that these channels are critical determinants of their cold temperature threshold.

\section{BCTC eliminates cold- and menthol-} evoked transduction currents

To examine directly the effects of BCTC on native $I_{\text {cold }}$ currents, we performed wholecell recordings on CS trigeminal neurons voltage clamped at a potential of $-60 \mathrm{mV}$. Figure $5 A$ shows current responses to three consecutive cooling ramps to $\sim 18^{\circ} \mathrm{C}$ from a starting temperature of $35^{\circ} \mathrm{C}$. In control solution, cooling induced an inward current that faded rapidly during rewarming. In the presence of $3 \mu \mathrm{M}$ BCTC, the coldinduced inward current was fully blocked, recovering partially during wash. To monitor the characteristics and the reversal potential of the cold-sensitive current in trigeminal neurons, we applied 1-s-duration 
voltage ramps ( -100 to $+100 \mathrm{mV})$ at different temperatures. As shown in Figure $5 B$, the native cold-sensitive current reversed close to $0 \mathrm{mV}(-4.0 \pm 2.3 \mathrm{mV} ; n=$ 4) and had notable outward rectification $\left(I_{+80 \mathrm{mV}} / I_{-80 \mathrm{mV}}\right.$ of $\left.10.6 \pm 6.1 ; n=4\right)$, similar to the properties of $I_{\text {TRPM8 }}$ in HEK293 cells. Furthermore, the current blocked by BCTC had similar rectification properties $\left(I_{+80 \mathrm{mV}} / I_{-80 \mathrm{mV}}\right.$ of $7.1 \pm 4.0$; $n=4 ; p=0.65)$ and identical reversal potential as $I_{\text {cold }}\left(V_{\text {rev }}\right.$ of $-4.0 \pm 1.8 \mathrm{mV} ; n=$ $4 ; p=0.99$ ). Only at very positive potentials did both currents deviate, indicating incomplete block of $I_{\text {cold }}$ by BCTC at these voltages. These results strongly support the tenet that both currents are carried by the same type of nonselective, cold-sensitive channels, most likely TRPM8.

The bar histogram in Figure 5C summarizes the effects of 1 and $3 \mu \mathrm{M} \mathrm{BCTC}$ on the amplitude of native $I_{\text {cold. }}$. In 16 of 17 cells tested, $3 \mu \mathrm{M}$ BCTC reduced $I_{\text {cold }}$ from $164 \pm 31$ to $6 \pm 2 \mathrm{pA}(p<0.001$, paired $t$ test). In one neuron, the amplitude of the current was unaffected by $3 \mu \mathrm{M}$ BCTC. We hypothesized that cold-sensitive but BCTC-insensitive neurons may represent a distinct population of thermosensitive neurons lacking TRPM8 expression. To test this possibility, we performed a second calcium imaging screen in cultured TG neurons derived from neonatal animals, looking for cold-sensitive neurons insensitive to $100 \mu \mathrm{M}$ menthol. Only 12 of 203 (6\%) were insensitive to the stimulating and/or sensitizing effect of menthol. During patch-clamp recordings, these cells displayed small inward currents during cooling that lacked the increase in membrane noise at low temperatures characteristic of BCTC-sensitive currents (Fig. 5D). In agreement with our hypothesis, in three of these neurons in which $3 \mu \mathrm{M}$ BCTC was tested, $I_{\text {cold }}$ was unaffected by the drug.

Figure $5 D$ shows the temperature dependence of the inward current $\left(V_{\mathrm{h}}\right.$ of $\left.-60 \mathrm{mV}\right)$ in a CS trigeminal neuron. The current had a threshold of $34.5^{\circ} \mathrm{C}$, reaching a maximum at $\sim 21^{\circ} \mathrm{C}$ and inactivating partially during the ramp. The mean threshold temperature of $I_{\text {cold }}$ was $31.1 \pm 0.4^{\circ} \mathrm{C}$ in trigeminal neurons recorded in control solution $(n=25)$. In the presence of $1 \mu \mathrm{M}$ BCTC, the cold-evoked inward current was reduced and the threshold shifted to colder temperatures (Fig. $5 D$ ). In six neurons with measurable currents, threshold temperature shifted from $32.9 \pm 0.7^{\circ} \mathrm{C}$ in control to $27.3 \pm 1.5^{\circ} \mathrm{C}$ in $1 \mu \mathrm{M}$ BCTC $(p=0.012)$. Finally, in $3 \mu \mathrm{M} \mathrm{BCTC,} \mathrm{the} \mathrm{amplitude} \mathrm{of} \mathrm{the}$ current was nearly abolished in this cell (Fig. $5 D$ ).

In an additional set of trigeminal CS neurons, the effect of BCTC was tested on currents evoked by $500 \mu \mathrm{M}$ menthol $\left(I_{\text {men }^{-}}\right.$ thol) at a temperature of $34-35^{\circ} \mathrm{C}$. In control solution, a brief application of menthol produced a robust inward current $\left(V_{\text {hold }}\right.$ of $-60 \mathrm{mV}$ ) (Fig. 5E). In all cells tested $(n=5), 3 \mu \mathrm{M}$ BCTC produced a complete suppression of $I_{\text {menthol }}$ (Fig. $5 E$ ). In this
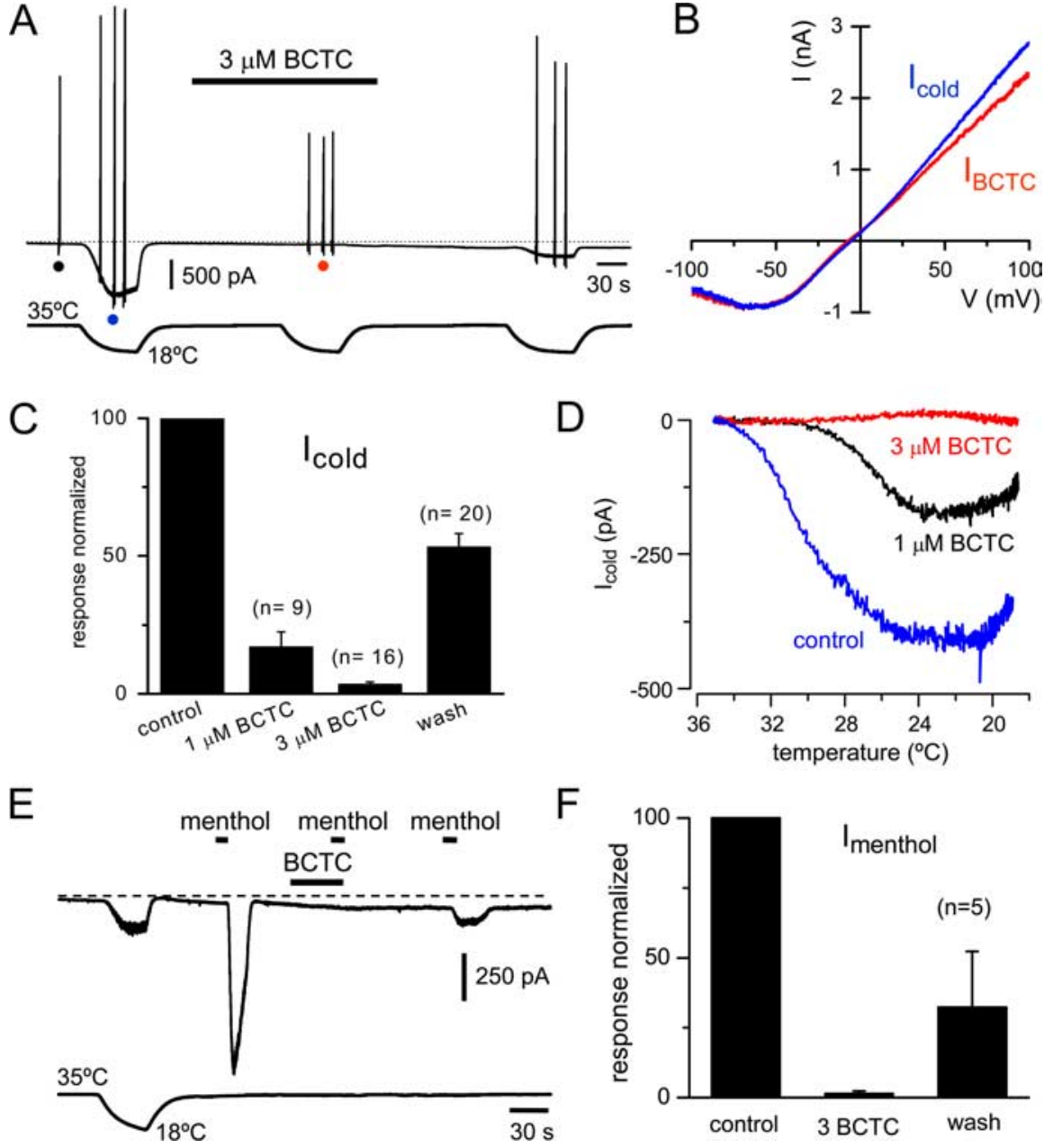

Figure 5. BCTC blocks currents induced by cooling and menthol in cold-sensitive trigeminal ganglion neurons. $\boldsymbol{A}$, Simultaneous ramps to a $C S$ neuron $\left(V_{\text {hold }}\right.$ of $\left.-60 \mathrm{mV}\right)$. The spike-like currents are the responses to voltage ramps $(-100$ to $+100 \mathrm{mV})$. Application of $3 \mu \mathrm{m} \mathrm{BCTC}$ fully blocked $I_{\text {cold }}$. The dotted line represents the 0 holding current. $\boldsymbol{B}$, Current-voltage relationship of (blue trace) and BCTC-sensitive (red trace) current obtained during the voltage ramps. To derive the coldsensitive current, the ramp current at $35^{\circ} \mathrm{C}$ (black dot) was subtracted from the current at $20^{\circ} \mathrm{C}$ (blue dot). To derive the BCTC-sensitive , the ramp current at $20^{\circ} \mathrm{C}$ in BCTC (red dot) was subtracted from the current at $20^{\circ} \mathrm{C}$ in control solution (blue dot). C, Bar histogram in the presence of $1 \mu \mathrm{m}$ (blacktrace) and $3 \mu \mathrm{m}$ (red trace) BCTC Notethemarked shiftin temperaturethreshold. . Simultaneous recording of membrane current (top trace) and bath temperature (bottom trace) during thermal and chemical (500 $\mu \mathrm{m}$ menthol) activation of a CS neuron $\left(V_{\text {hold }}\right.$ of $\left.-60 \mathrm{mV}\right)$. $\boldsymbol{F}$, Bar histogram summarizing the block of $I_{\text {menthol }}$ by $3 \mu \mathrm{m} \mathrm{BCTC}$.

case, reversibility was more variable, in part attributable to a more pronounced desensitization during repeated applications of menthol at high concentration. Thus, these data show that 3 $\mu \mathrm{M}$ BCTC also produced a complete blockade of temperaturegated or chemically gated currents in a large fraction of trigeminal cold thermoreceptor neurons.

\section{Effects of BCTC on cold-evoked transduction currents are specific}

To rule out the possibility that the effects of BCTC resulted of a nonspecific action on spike generation conductances rather than on cold-evoked transduction currents, we compared the effects of BCTC on current-evoked (500 pA ramp in 1 s) and coldevoked electrogenesis during current-clamp recordings in the same cells. As shown in Figure 6A, cooling depolarized CS neurons reversibly, with a mean threshold of 30.4. $\pm 0.4^{\circ} \mathrm{C}(n=13)$. The average depolarization was $11.1 \pm 0.9 \mathrm{mV}(n=13)$, and all 
A

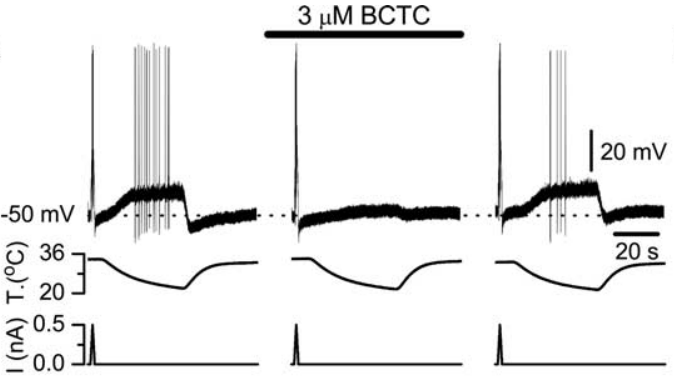

C

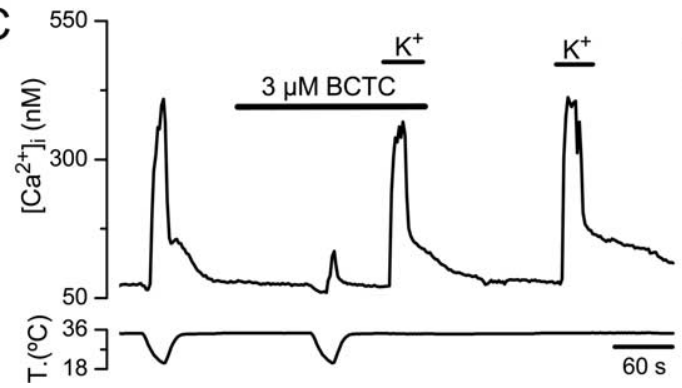

B

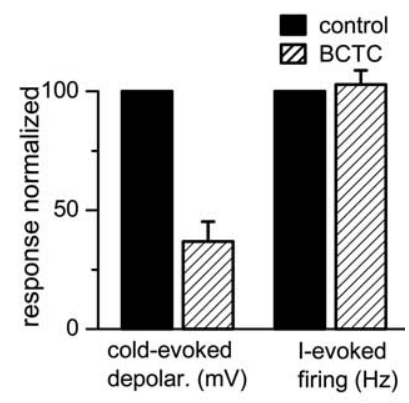

D

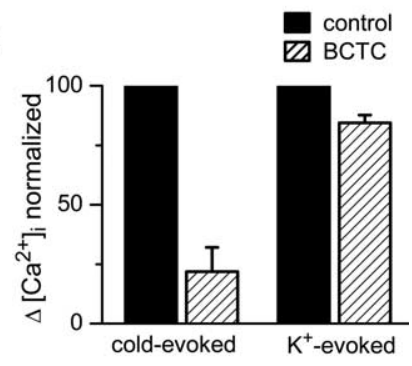

Figure 6. BCTC blocks cold-induced generator potentials in cold-sensitive trigeminal ganglion neurons. $A$, Simultaneous recording of membrane potential (top trace), bath temperature (middle trace), and membrane current (bottom trace) during three consecutive cooling ramps to a cold-sensitive TG neuron recorded in current-clamp mode $\left(I_{\text {hold }}\right.$ of $\left.0 \mathrm{pA}\right)$. Application of $3 \mu \mathrm{M}$ $B C T C$ produced a reversible reduction in the cold-induced depolarization without affecting the voltage response to a $500 \mathrm{pA} \mathrm{ramp}$. The dotted line represents the initial resting membrane potential. $\boldsymbol{B}$, Bar histogram of normalized responses to cooling and to l-evoked firing in control solution (black bars) and in $3 \mu \mathrm{M} \mathrm{BCTC} \mathrm{(stripped} \mathrm{bars).} \mathrm{C,} \mathrm{Simultaneous} \mathrm{recording} \mathrm{of}\left[\mathrm{Ca}^{2+}\right]_{\mathrm{i}}$ (top trace) and bath temperature (bottom trace) during two consecutive cooling steps to a cold-sensitive TG neuron. BCTC at $3 \mu \mathrm{m}$ produced a large reduction in the cold-induced response with only minor effects on the depolarization-induced response produced by a 30 mm elevation in extracellular $\mathrm{K}^{+}$. D, Bar histogram of normalized $\left[\mathrm{Ca}^{2+}\right]_{\mathrm{i}}$ responses to cooling and to elevated $\mathrm{K}^{+}$in control solution (black bars) and in $3 \mu \mathrm{M}$ BCTC (striped bars). The reduction in BCTC is significant in both cases ( $p<0.0001$ for cold-evoked responses and $p<0.001$ for $\mathrm{K}^{+}$-evoked responses).

neurons reached the firing of action potentials at an average threshold of $26.5 \pm 0.7^{\circ} \mathrm{C}$. In the same population of cells, depolarization by cold in the presence of BCTC was reduced to $4.9 \pm$ $0.9 \mathrm{mV}(p<0.001)$, and only three cells reached AP threshold. The effects of BCTC were reversible. Notably, spiking responses to depolarizing intracellular current pulses were essentially unaffected by BCTC (Fig. 6B). Moreover, as shown in Table 1, $3 \mu \mathrm{M}$ BCTC had no effect on the duration and amplitude of the action potential, input resistance, rheobase, and current-evoked firing frequency of CS neurons.

The specific nature of BCTC blockade on cold-evoked activity was also verified during calcium imaging experiments. Figure $6 \mathrm{C}$ shows the effect of $3 \mu \mathrm{M}$ BCTC on $\left[\mathrm{Ca}^{2+}\right]_{\mathrm{i}}$ responses evoked by two consecutive cold ramps and two brief applications of elevated extracellular $\mathrm{K}^{+}(30 \mathrm{~mm})$. Whereas the cold-evoked activity was almost fully suppressed by BCTC, the depolarization-evoked $\left[\mathrm{Ca}^{2+}\right]_{\mathrm{i}}$ increase was well preserved. The bar diagrams in Figure $6 \mathrm{D}$ summarize the results obtained in $10 \mathrm{CS}$ neurons using this protocol.

Altogether, these results indicate that the effects of $3 \mu \mathrm{M}$ BCTC are selective and complete on cold transduction currents, with minor blocking effects on voltage-gated ion channels.

\section{BCTC does not block activity of TRPA1 channels}

TRPAl is the second TRP channel postulated to be activated by cold temperatures, with a reported threshold of $18^{\circ} \mathrm{C}$ (Story et al., 2003). In addition, TRPA1 is activated by a number of pungent compounds, such as cinnamaldehyde, allycin, and mustard oil (Bandell et al., 2004; Jordt et al., 2004). Unexpectedly, $3 \mu \mathrm{M}$ BCTC produced a robust activation of TRPA1 channels ex-

pressed in HEK293 cells (supplemental Fig. 2, available at www.jneurosci.org as supplemental material). This effect of BCTC was observed during both $\left[\mathrm{Ca}^{2+}\right]_{i}$ imaging experiments (supplemental Fig. $\mathrm{S} A$, available at www.jneurosci.org as supplemental material) and whole-cell recordings (supplemental Fig. $2 C, D$, available at www.jneurosci.org as supplemental material). In contrast to the powerful blocking effects on TRPM8 channels, BCTC had no significant blocking effects on TRPA1 activity evoked by application of cinnamaldehyde (supplemental Fig. $2 F, G$, available at www.jneurosci.org as supplemental material). The stimulatory actions of BCTC on TRPA1 activity were not apparent on native channels: we never observed $\left[\mathrm{Ca}^{2+}\right]_{\mathrm{i}}$ elevations in the soma of cultured sensory neurons or increased firing in corneal nerve terminals with BCTC, even in those activated by cinnamaldehyde (data not shown).

\section{Functional characteristics of cold- sensitive corneal thermoreceptor endings}

To examine the effects of BCTC on coldevoked activity in sensory nerve terminals, we turned to an in vitro preparation of the guinea pig cornea (Brock et al., 1998). These types of recordings have been unsuccessful in mice. Therefore, to exclude potential species differences in pharmacological properties of TRPM8 channels, we verified first the effects of BCTC on menthol- and cold-evoked activity in cultured guinea pig trigeminal sensory neurons loaded with fura-2. As shown in Figure $7 A-C$, menthol responses in cold-sensitive neurons of guinea pig were also fully and reversibly blocked by $3 \mu \mathrm{M}$ BCTC $(n=7 ; p<$ $0.001)$. Next we investigated the sensitivity of cold-evoked responses to BCTC in 20 guinea pig trigeminal neurons. The findings were qualitatively similar to those obtained in mice in that we identified the same three phenotypes of sensory neurons. In $25 \%$, cold-evoked responses were fully and reversibly blocked by $3 \mu \mathrm{M}$ BCTC (Fig. 7D). Furthermore, in three of three of these neurons, cold-evoked responses were potentiated by $100 \mu \mathrm{M}$ menthol (Fig. $7 D$ ), suggesting that they are mediated by activation of TRPM8 channels. In $20 \%$ of the neurons, cold-evoked $\left[\mathrm{Ca}^{2+}\right]_{\mathrm{i}}$ responses were unaffected by BCTC (Fig. 7E). In this subpopulation $(n=$ 4 ), menthol produced no activation or potentiation of the coldevoked response, suggesting that it is independent of TRPM8 activity (Fig. $7 E$ ). Finally, in a third group comprising $55 \%$ of neurons, the cold-evoked response was partially blocked by BCTC. In five of six cells tested, there was an excitatory effect of menthol. These findings indicate a clear correlation between menthol responsiveness and BCTC blocking action, full or partial, among cold-sensitive neurons. The principal difference with mouse was a larger proportion (20 vs $8 \%$ ) of cold-sensitive but BCTC- and menthol-insensitive neurons ( $p=0.089$, Fisher's exact test).

Figure $8 A$ shows a typical example of the effects of temperature decrease on the occurrence of NTIs in a single CS receptor fiber of the eye cornea recorded extracellularly with a patch pi- 
pette. These cold receptors were characterized by the spontaneous, regular firing of NTIs at resting temperatures of $34-36^{\circ} \mathrm{C}$ and the accelerating increase in firing frequency, often in bursts, when cooling pulses were applied (Fig. $8 \mathrm{~B}$ ). Rewarming silenced transiently the receptor terminal discharge, which resumed gradually during the recovery to the initial resting temperature (Fig. $8 A$ ). Table 2 shows different parameters of NTI frequency discharge at resting temperature, during cooling and during various pharmacological manipulations (see below) in corneal cold thermoreceptor fibers.

\section{Lack of effect of BCTC on spontaneous and cold-evoked activity in corneal sensory terminals}

We next tested the effect of perfusing BCTC on NTI activity in 17 corneal terminals. Curiously, the mean spontaneous NTI firing frequency at $35^{\circ} \mathrm{C}$ was not significantly modified by perfusion with high concentration $(10 \mu \mathrm{M})$ of BCTC (Fig. $8 A, B)$. The mean NTI frequency was $8.5 \pm 0.9 \mathrm{~Hz}$ in control and $8.6 \pm 0.9 \mathrm{~Hz}$ in BCTC ( $p=0.8)$; firing rate was reduced $>20 \%$ in only 2 of the 17 terminals, the majority showing a modest increase of $5-10 \%$ in rate. Furthermore, effects of BCTC on cold-evoked increases in activity were also very modest in the cornea. In $65 \%$ of the terminals $(n=17)$, BCTC had no effect on NTI discharge, including maximum response, cooling threshold, and temperature required to silence the cold-induced NTI discharge during rewarming (warming threshold) (Fig. $8 \mathrm{~A}$, Table 2). The typical burst pattern of NTI discharge during cooling was also unaffected by BCTC (Fig. $8 \mathrm{~B}$ ). In the remaining six cold-sensitive endings, the spontaneous activity at $35^{\circ} \mathrm{C}$ was equally not altered, but the peak frequency value evoked by the cold ramp was reduced between 25 and $50 \%$ of the pretreatment values and the mean cold temperature threshold shifted ( $0.9 \pm$ $0.3^{\circ} \mathrm{C}$ ) to cooler values. The endings exhibiting some degree of sensitivity to BCTC in their response to cooling were undistinguishable from insensitive endings in their mean spontaneous firing frequency, cold threshold temperature, or peak frequency of the cold response before treatment (Table 2).

\section{Expression of TRPM8 channels in corneal thermoreceptor nerve endings and effects of BCTC on menthol-evoked NTI activity}

The modest effect of BCTC on cold-evoked activity in corneal endings cannot be attributed to the lack of expression of TRPM8 channels. Indeed, application of menthol to the bath solution at $35^{\circ} \mathrm{C}$ produced a dose-dependent increase in the basal activity in single cold nerve terminals (Fig. 9A). At a concentration of $5 \mu \mathrm{M}$, menthol already evoked a significant increase in firing frequency, whereas at $100 \mu \mathrm{M}$, its application resulted in a robust effect in all of the CS terminals tested $(n=22)$, with the mean basal frequency more than doubling (Fig. $9 A, B$ ). The $\mathrm{EC}_{50}$ of the re- sponse to menthol, computed as percentage increase over baseline activity, had a value of $20 \mu \mathrm{M}$ (Fig. 9B). In addition, menthol produced an increase in the maximal cold-evoked response (Fig. $9 C$ ) and a deviation to warmer temperatures of the threshold temperature required to evoke a cold response (Table 3 ). These results strongly suggest that TRPM8 channels are functional in all CS nerve terminals of the cornea.

In contrast to the modest inhibition of BCTC on cold-evoked responses in corneal endings, menthol-evoked activity was completely abrogated by BCTC. As shown in Figure 9A, the inhibitory effects of BCTC on menthol-evoked NTI activity were fully reversible. In 17 additional nerve endings tested, exposure of the cornea to $10 \mu \mathrm{M}$ BCTC completely abolished the increase in spontaneous firing, the shift in temperature threshold to cooling pulses, and the enhanced response to cooling evoked by $100 \mu \mathrm{M}$ menthol (Table 3). After washout of BCTC, the typical potentiating effects of menthol on cold-evoked activity were apparent (Fig. 9C). Figure 9D summarizes the effects of BCTC on coldevoked responses in control solution and in the presence of menthol. It is evident that BCTC prevents the sensitizing effects of menthol on the terminal. In addition, this result indicates that the insensitivity of the terminals to BCTC effects during cooling is not attributable to a poor access of the drug or a different pharmacological profile of the receptor at the endings. 


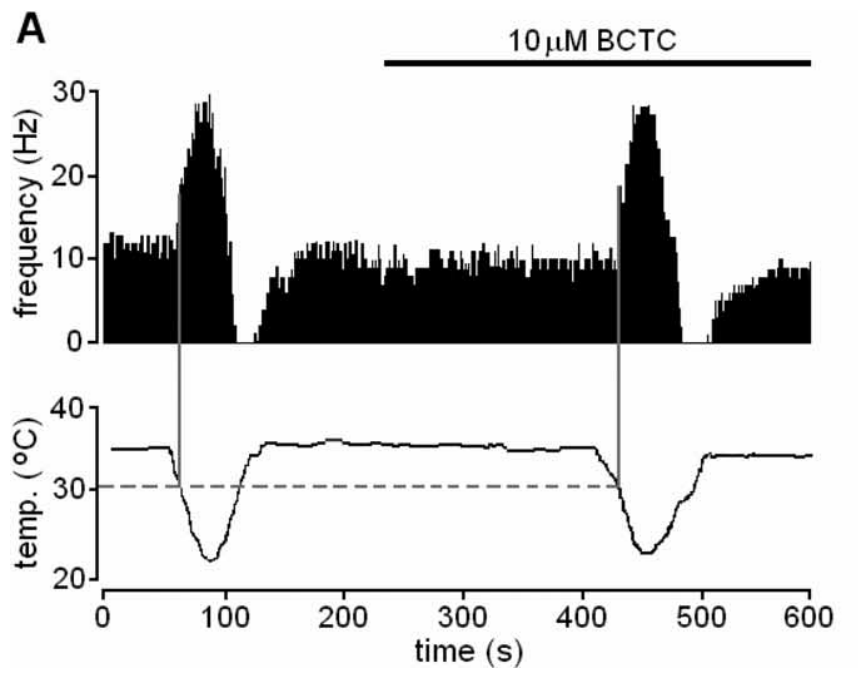

B control

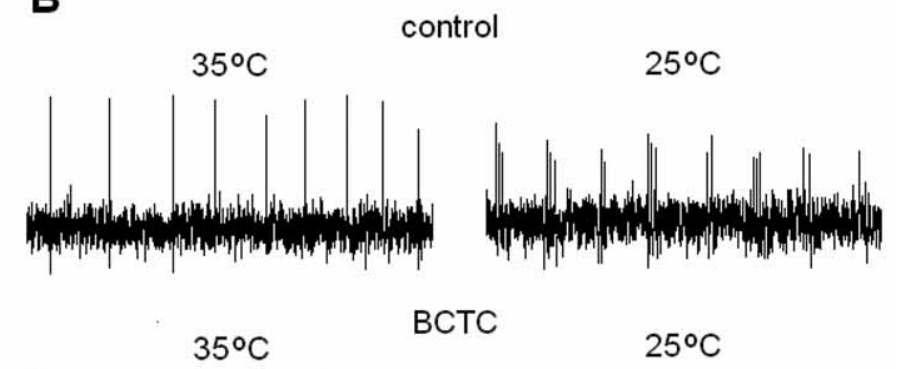

Figure 8. Lack of effect of BCTC on spontaneous and cold-evoked activity in corneal sensory endings. A, Activity in a corneal CS receptor during two consecutive cooling cycles, in control solution, and during perfusion with $10 \mu \mathrm{m}$ BCTC. The bottom trace shows the temperature of the bathing solution recorded close to the corneal surface. The top trace shows the effect of changing temperature on the frequency of NTIs. The gray vertical bars mark the cold threshold, projected as a dotted line on the temperature scale. Note the lack of effect of $10 \mu \mathrm{m} B C T C$ on spontaneous and cold-evoked activity. $\boldsymbol{B}$, Each trace represents a $1 \mathrm{~s}$ original record of the terminal shown in $\boldsymbol{A}$, at the baseline temperature $\left(35^{\circ} \mathrm{C}\right)$, and at the peak of the cold response ( $\left.25^{\circ} \mathrm{C}\right)$. Note the complete lack of effect of $\mathrm{BCTC}$, on neither the mean firing frequency nor the pattern of discharge.

Table 2. Effects of $10 \mu \mathrm{M}$ BCTC on responses to cooling of cold-sensitive nerve terminals

\begin{tabular}{|c|c|c|c|c|c|c|c|c|}
\hline & \multicolumn{2}{|c|}{ Baseline activity (Hz) } & \multicolumn{2}{|c|}{ Cooling threshold $\left({ }^{\circ} \mathrm{C}\right)$} & \multicolumn{2}{|c|}{ Maximum response (\% of baseline) } & \multicolumn{2}{|c|}{ Warming threshold $\left({ }^{\circ} \mathrm{C}\right)$} \\
\hline & Control & $\mathrm{BCTC}$ & Control & $\mathrm{BCTC}$ & Control & $\mathrm{BCTC}$ & Control & $\mathrm{BCTC}$ \\
\hline All terminals $(n=17)$ & $8.5 \pm 0.9$ & $8.6 \pm 0.9$ & $31.9 \pm 0.3$ & $31.2 \pm 0.4$ & $272 \pm 18$ & $240 \pm 20$ & $28.5 \pm 1.6$ & $30.0 \pm 1.1$ \\
\hline Low BCTC sensitivity $(n=11)$ & $8.8 \pm 1.0$ & $9.2 \pm 1.1$ & $31.7 \pm 0.3$ & $31.1 \pm 0.5$ & $279 \pm 25$ & $271 \pm 25$ & $29.6 \pm 1.7$ & $30.1 \pm 1.3$ \\
\hline High BCTC sensitivity $(n=6)$ & $7.8 \pm 1.4$ & $7.5 \pm 1.6$ & $32.3 \pm 0.4$ & $31.5 \pm 0.4^{*}$ & $260 \pm 19$ & $182 \pm 14^{*}$ & $28.6 \pm 0.9$ & $29.3 \pm 1.3$ \\
\hline
\end{tabular}

Modest effect of SKF96365 on spontaneous and cold-evoked activity in corneal sensory terminals

SKF96365 is another drug with blocking actions on several TRP channels (Clapham et al., 2005; Wang and Poo, 2005), including cold-sensitive currents in primary sensory neurons (Reid et al., 2002). On rat recombinant TRPM 8 channels, we found an inhibition of $I_{\text {cold }}$ by SKF96365, with an $\mathrm{EC}_{50}$ of $0.8 \pm 0.1 \mu \mathrm{M}$ at +80 $\mathrm{mV}$ (our unpublished data), indicating that SKF96365 is also a potent blocker of TRPM8 channels. Therefore, we tested the effects of SKF96365 on NTI activity during cooling and menthol application in an additional set of 10 corneal terminals. These results are summarized in Table 4. Qualitatively, the findings were nearly identical to those obtained with BCTC. In 7 of the 10 terminals, application of $20 \mu \mathrm{M}$ SKF96365 produced no effect on the spontaneous or cold-evoked activity. A representative example is shown in Figure $10 \mathrm{~A}$. In the remaining three terminals, we observed modest but significant reductions in spontaneous and cold-evoked activity but no shifts in cooling or warming threshold (Table 4). A summary of mean effects of SKF96365 on normalized peak cold response is shown in Figure $10 \mathrm{~B}$. In contrast, and in full agreement with results obtained with BCTC, the enhancement in activity produced by $100 \mu \mathrm{M}$ menthol at baseline temperature $\left(\sim 32^{\circ} \mathrm{C}\right)$ was fully blocked by $20 \mu \mathrm{M}$ SKF96365 (Fig. $10 C)$. A summary of effects of SKF96365 on normalized menthol-evoked response is shown in Figure $10 \mathrm{D}$ for 10 corneal terminals.

\section{BCTC does not affect 4-AP-induced cold sensitivity}

Micromolar doses of 4-AP can render cold sensitive a large fraction of trigeminal sensory neurons by a mechanism that appears to be independent of TRPM8 expression (Viana et al., 2002). Indeed, as shown in supplemental Figure 3 (available at www. jneurosci.org as supplemental material), this subpopulation of sensory neurons remained insensitive to cold, even if cooling was applied in the presence of $100 \mu \mathrm{M}$ menthol $(n=27)$. In the absence of 4-AP, the amplitude of cold-evoked signals $\left[\mathrm{Ca}^{2+}\right]_{\mathrm{i}}$ in these neurons was $-4.1 \pm 1.2 \mathrm{nM}$. We asked whether BCTC could affect the 4-AP-induced cold sensitivity of this class of neurons. Thus, after turning these neurons cold sensitive by treatment with 4 -AP $(75 \mu \mathrm{M})$, we tested the effects of $3 \mu \mathrm{M}$ BCTC on cold-evoked $\left[\mathrm{Ca}^{2+}\right]_{\mathrm{i}}$ signals. As shown in supplemental Figure $3 D$ (available at www.jneurosci.org as supplemental material), 3 $\mu \mathrm{M}$ BCTC had no effect on the amplitude of cold-evoked responses: the $\left[\mathrm{Ca}^{2+}\right]_{\mathrm{i}}$ increase was $283 \pm 46 \mathrm{nM}$ in the presence of 4 -AP and $301 \pm 59 \mathrm{nM}$ in 4 -AP plus BCTC $(p>0.9 ; n=28)$. Temperature thresholds were also unaffected, with mean values of $27.5 \pm 0.6$ and $28.0 \pm 0.6^{\circ} \mathrm{C}$ in the absence and presence of BCTC, respectively ( $p>0.4 ; n=28$ ). These results indicate that effects of BCTC on cold sensitivity appear to be highly selective for neurons expressing TRPM8 channels in their membrane.

\section{Discussion}

In the present study, we explored the contribution of TRPM8 channels to cold sensing in trigeminal ganglion neurons and in corneal receptor endings. First, we characterized the blocking effects of BCTC on cold- and menthol-activated currents in recombinant TRPM8 channels. Subsequently, we used BCTC to probe native TRPM8 channels in the soma and endings of cold thermoreceptors. The results obtained with BCTC were validated with SKF96365, a broader-spectrum TRP channel blocker. We reach the 
following main conclusions. First, BCTC is a potent blocker of recombinant and native TRPM8 channels. Second, in the soma of the majority of cultured mouse cold-sensitive trigeminal ganglion neurons, activation of BCTC-sensitive channels, presumably TRPM8 channels, participate in the depolarizing responses, firing, and secondary intracellular calcium elevations evoked by cold. Third, the contribution of TRPM 8 to cold responses in sensory neurons spans a wide range of temperatures, with thresholds significantly warmer than those reported in previous expression studies. Fourth, in trigeminal corneal cold receptor endings, TRPM8 plays no role in the spontaneous discharge activity typical of cold thermoreceptors. Fifth, blockade of TRPM8 channels at corneal sensory endings produces a selective reduction of menthol-mediated activation, with only a minor impairment in their ability to transduce cold stimuli.

\section{Specific effects of BCTC on TRPM8 channels}

The conclusions of this study are critically dependent on the postulate that BCTC effects on cold sensing are attributable to a specific blockade of TRPM8 channels. This view is supported by several independent pieces of evidence. BCTC was identified as a potent and selective blocker of TRPV1 channels (Valenzano et al., 2003). Subsequent work showed that BCTC is also a full blocker of menthol-evoked responses in mouse (Behrendt et al., 2004) and human (Weil et al., 2005) TRPM8 channels. We confirmed the effects of BCTC on menthol-evoked signals in mouse and guinea pig TRPM8 channels and extended these results to cold-evoked currents. According to the present data, BCTC is the most potent blocker of TRPM8 channels reported to date. Other TRPV1 blockers, such as capsazepine, also block TRPM8 channels, albeit less potently (Reid et al., 2002; Behrendt et al., 2004; Weil et al., 2005), suggesting a partial overlap in ligand actions on these two TRP channels. The blocking action of BCTC on TRPV1 channels should not affect our interpretation because their threshold temperature $\left(\sim 42^{\circ} \mathrm{C}\right)$ (Caterina et al., 1997) is much higher than the temperatures reached during our stimulation protocol.

In an extensive screen of BCTC effects on ion channels and receptors performed by Valenzano et al. (2003), BCTC proved to be a highly specific TRPV1 antagonist (actions on TRPM8 were not tested in that study). Furthermore, BCTC does not block agonist-evoked ( $\alpha$-phorbol 12,12-didecanoate) $\left[\mathrm{Ca}^{2+}\right]_{\mathrm{i}}$ signals in TRPV4-transfected cells (Behrendt et al., 2004). Additionally, we show that BCTC has minimal effects on the intrinsic excitability and action potential parameters of CS trigeminal ganglion neurons and nerve terminals. Finally, in our experiments, cold sensitivity depending on the activation of ion channels other than TRPM8 was completely unaffected by BCTC. In summary, the specificity and reversibility of BCTC blockade of certain thermoTRP channels (i.e., TRPV1 and TRPM8) make this drug a very useful tool to analyze their role in temperature transduction and nociception.
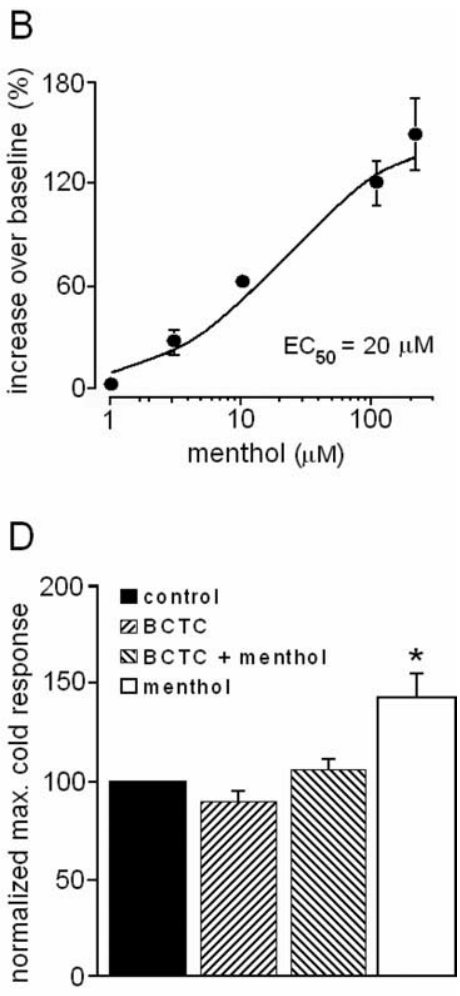

Figure 9. Effect of BCTC on menthol-evoked NTI activity in corneal cold thermoreceptor nerve endings. $A$, Application of $10 \mu \mathrm{M}$ BCTC blocks the enhancement in NTI activity produced by $100 \mu \mathrm{m}$ menthol. $\boldsymbol{B}$, Dose-response curve of menthol effects on the

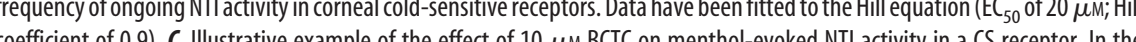
presence of BCTC, application of menthol did not augment ongoing NTI activity. After BCTC removal, the spontaneous NTI discold-evoked activity also increased. D, Summary of menthol (100 $\mu \mathrm{m})$ and BCTC (10 $\mu \mathrm{m})$ effects on cold-evoked responses $(n=17)$. Results have been normalized to those obtained in control solution. Only the response in menthol is significantly different from the rest (ANOVA test, ${ }^{*} p<0.05$ ).

The molecular mechanism of action of BCTC still needs to be fully identified. BCTC produces an apparent dose-dependent shift in temperature activation threshold of menthol- and coldevoked currents. At neutral $\mathrm{pH}$, the ionization of BCTC is very low (with an estimated ratio between charged vs neutral forms $<0.0002)$. This suggests that the apparent voltage dependence of TRPM8 block is not attributable to a direct interaction of BCTC with charged particles within the membrane electric field.

\section{Contribution of TRPM8 to cold sensing in the soma of cultured primary sensory neurons}

BCTC produced a powerful inhibition of cold-evoked responses in the soma of the majority $(>90 \%)$ of mouse CS trigeminal ganglion neurons in culture, and this inhibition was specific to the TRPM8 ${ }^{+}$subpopulation of neurons. This percentage appeared to be somewhat lower in guinea pigs. The inhibition by BCTC of the response to cooling was manifested even in the case of neurons activated by very small temperature decreases (i.e., low-threshold cold thermoreceptors). This strongly suggests that the functional operating range of native TRPM8 channels in CS neurons is far warmer (i.e., they have a lower threshold) than inferred by measurements obtained in expression studies (for review, see McKemy, 2005; Reid, 2005), spanning the entire physiological temperature range of native cold receptors (Hensel, 1981). Recently, we showed that the temperature threshold of menthol- and cold-sensitive, TRPM $8{ }^{+}$cultured trigeminal ganglion neurons was much lower than that of hippocampal neurons 
Table 3. Effects of $10 \mu \mathrm{M}$ BCTC on responses to cooling of cold-sensitive nerve terminals in the presence of $100 \mu \mathrm{m}$ menthol

\begin{tabular}{|c|c|c|c|c|c|c|c|c|}
\hline & \multicolumn{2}{|c|}{ Baseline activity (Hz) } & \multicolumn{2}{|c|}{ Cooling threshold $\left({ }^{\circ} \mathrm{C}\right)$} & \multicolumn{2}{|c|}{ Maximum response ( $\%$ of baseline) } & \multicolumn{2}{|c|}{ Warming threshold $\left({ }^{\circ} \mathrm{C}\right)$} \\
\hline & Control & $\mathrm{BCTC}$ & Control & BCTC & Control & $\mathrm{BCTC}$ & Control & $\mathrm{BCTC}$ \\
\hline All terminals $(n=17)$ & $12.9 \pm 1.5$ & $7.9 \pm 0.9^{*}$ & $33.3 \pm 0.2$ & $28.5 \pm 1.6$ & $262 \pm 19$ & $300 \pm 19$ & $32.9 \pm 0.9$ & $30.1 \pm 1.0^{*}$ \\
\hline Low BCTC sensitivity $(n=11)$ & $13.3 \pm 1.9$ & $9.4 \pm 1.4^{*}$ & $33.2 \pm 0.2$ & $29.7 \pm 1.8$ & $276 \pm 26$ & $308 \pm 22$ & $32.9 \pm 1.0$ & $30.4 \pm 0.9^{*}$ \\
\hline High BCTC sensitivity $(n=6)$ & $12.2 \pm 2.2$ & $7.1 \pm 1.5^{*}$ & $33.4 \pm 0.3$ & $28.6 \pm 0.9$ & $240 \pm 16$ & $274 \pm 31$ & $32.9 \pm 0.9$ & $29.4 \pm 1.1^{*}$ \\
\hline
\end{tabular}

Table 4. Effects of $20 \mu \mathrm{M}$ SKF96365 on responses to cooling of cold-sensitive nerve terminals

\begin{tabular}{|c|c|c|c|c|c|c|c|c|}
\hline & \multicolumn{2}{|c|}{ Baseline activity (Hz) } & \multicolumn{2}{|c|}{ Cooling threshold $\left({ }^{\circ} \mathrm{C}\right)$} & \multicolumn{2}{|c|}{ Maximum response (\% of baseline) } & \multicolumn{2}{|c|}{ Warming threshold $\left({ }^{\circ} \mathrm{C}\right)$} \\
\hline & Control & SKF & Control & SKF & Control & SKF & Control & SKF \\
\hline All terminals $(n=10)$ & $7.8 \pm 0.8$ & $7.0 \pm 0.9$ & $30.1 \pm 0.5$ & $29.2 \pm 0.8$ & $295 \pm 27$ & $291 \pm 35$ & $27.1 \pm 1.1$ & $25.7 \pm 1.1$ \\
\hline Low SKF sensitivity $(n=7)$ & $7.0 \pm 0.9$ & $7.1 \pm 1.3$ & $30.5 \pm 0.7$ & $29.1 \pm 1.1$ & $317 \pm 35$ & $349 \pm 28$ & $27.6 \pm 1.5$ & $25.8 \pm 1.4$ \\
\hline High SKF sensitivity $(n=3)$ & $9.6 \pm 0.8$ & $6.8 \pm 1.0^{*}$ & $29.4 \pm 0.8$ & $29.4 \pm 1.0$ & $245 \pm 22$ & $155 \pm 6^{*}$ & $25.8 \pm 0.8$ & $25.5 \pm 1.9$ \\
\hline
\end{tabular}

Baseline temperature, $32.0 \pm 0.6^{\circ} \mathrm{C}\left(29.0-35.8^{\circ} \mathrm{C}\right)$. Minimum temperature during cooling, $22.1 \pm 0.3^{\circ} \mathrm{C}\left(20.8-23.5^{\circ} \mathrm{C}\right){ }^{*} p<0.05$, paired $t$ test.

A

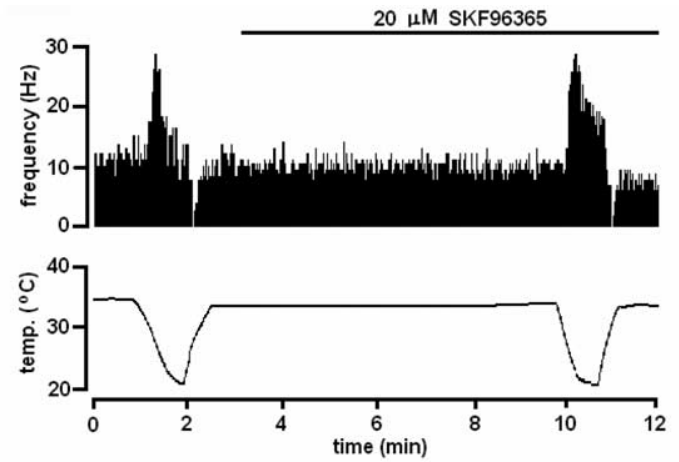

C

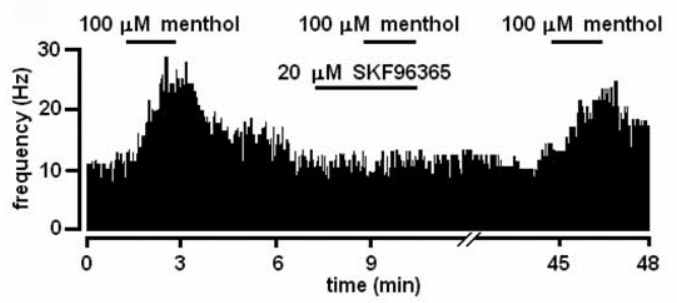

B

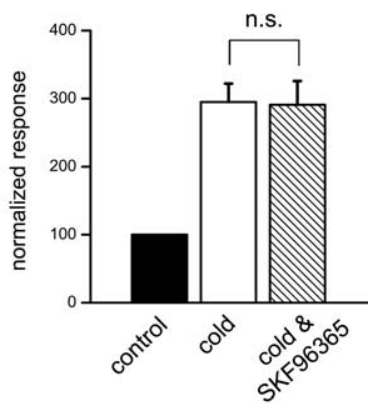

D

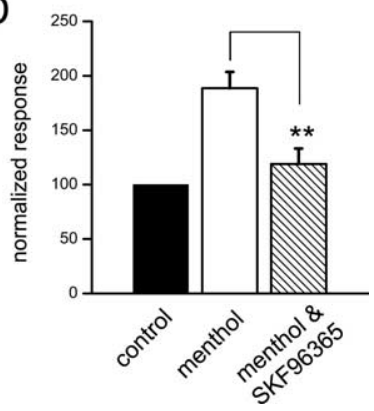

Figure 10. Effect of SKF96365 on cold and menthol-evoked NTI activity in corneal cold thermoreceptor nerve endings. $\boldsymbol{A}$, Activity in a corneal CS receptor during two consecutive cooling cycles, in control solution, and during perfusion with $20 \mu \mathrm{m}$ SKF96365. The bottom trace shows the temperature of the bathing solution recorded close to the corneal surface. The top trace shows the effect of changing temperature on the frequency of NTIs. Note the lack of effect of $20 \mu \mathrm{m}$ SKF96365 on spontaneous and cold-evoked activity. B, Summary histogram of effects of $20 \mu \mathrm{m}$ SKF96365 on cold-evoked activity $(n=10)$. For each terminal, cold-evoked activity has been normalized to the mean frequency at static temperature $\left(32-34^{\circ} \mathrm{C}\right)$ before application of SKF96365. The drug did not produce a significant inhibition of the cold-evoked response. C, Application of $20 \mu \mathrm{M}$ SKF96365 blocks reversibly the enhancement in NTI activity produced by $100 \mu \mathrm{m}$ menthol at a baseline temperature of $34^{\circ} \mathrm{C}$. D, Summary histogram of effects of $20 \mu \mathrm{m}$ SKF96365 on menthol-evoked activity $(n=10)$. For each terminal, menthol-evoked activity has been normalized to the mean frequency at static temperature $\left(32-34^{\circ} \mathrm{C}\right)$ in control solution, before application of SKF96365. The drug produce a highly significant inhibition of the menthol-evoked response $(* * p<0.001)$.

transiently transfected with recombinant TRPM8 channels (de la Pena et al., 2005) and hypothesized that TRPM8 channels could be modulated intrinsically to shift their activation threshold. Thus far, very little is known about sensitizing agents of native TRPM8 channels. Elevated intracellular phosphatidylinositol-4, 5-biphosphate levels increase the amplitude of TRPM8 currents in transfected cells (Liu and Qin, 2005; Rohacs et al., 2005). Also, acute application of nerve growth factor to DRG neurons shifts their cold thresholds to warmer values (Reid et al., 2002). Another modulatory mechanism of TRPM8 channels is their PKC-dependent phosphorylation state (Premkumar et al., 2005).

Nonessential role of TRPM8 channels in cold-sensitive nerve terminals of the cornea

The basal activity of cold thermoreceptor fibers has been attributed to a rhythmic oscillation of membrane potential in their endings that generates repetitive firing of action potentials (Braun et al., 1980). The identification of TRPM8 as a thermosensitive channel expressed by cold- and menthol-sensitive primary sensory neurons led to the proposal that cooling increases the opening probability of TRPM8, thus generating a depolarizing inward current that augments the firing frequency of cold thermoreceptor terminals (for review, see McKemy, 2005; Reid, 2005).

Our work in the isolated cornea confirms previous studies showing that this tissue is innervated by cold- and mentholsensitive sensory fibers (Gallar et al., 1993; Brock et al., 2001; Acosta et al., 2001; Carr et al., 2003) that exhibit rhythmic ongoing activity and response characteristics typical of innocuous cold receptor fibers previously described in the trigeminal territory (Hensel and Wurster, 1970; Schafer et al., 1988). BCTC did not affect the spontaneous activity of corneal cold receptor endings. The inhibitory effects of SKF96365 were also very modest. Such static discharge encodes the absolute temperature of the exposed surface (Carr et al., 2003). Therefore, our data indicate that TRPM8 channels present in the endings are not responsible for their background impulse activity, suggesting that activity in the basal oscillator is essentially independent of TRPM8 channels. Cold-sensitive neurons have a strong expression of other inward currents that could play a role in spontaneous firing, including pacemaker channels of the HCN family and low-threshold calcium channels (Viana et al., 2002).

In approximately two-thirds of the corneal cold receptor end- 
ings, increases in NTI firing frequency evoked by cooling pulses were not modified by saturating concentrations of BCTC or SKF96365. In the remaining endings, both drugs caused a very modest reduction of the peak firing frequency evoked by cooling. In contrast, the strong stimulating effect of menthol on NTI discharges, observed in all cold receptor endings of the cornea, was fully blocked by BCTC and SKF96365. This indicates first that the endings express TRPM8 channels that are fully accessible to the drug and also that these channels play at best a minor role in the generation of the augmented impulse discharges evoked by mild temperature reductions.

It is unlikely that the resistance of guinea pig cold-sensitive terminals to blockade by BCTC can be attributed to species differences in the pharmacological profile of TRPM8 channels. Menthol-evoked responses in cold-sensitive neurons were abrogated by even lower concentrations of BCTC, also in guinea pigs. Furthermore, all cold-sensitive endings in the cornea are excited by menthol, and this sensitivity is also fully blocked by BCTC and SKF96365, strongly suggesting that TRPM8 activity in the terminals is also abrogated. Remarkably, nearly all BCTC-insensitive neurons were also insensitive to menthol, strongly suggesting the presence of a TRPM8-independent cold-sensing mechanism. Thus, the most parsimonious explanation of our results is that, in the corneal terminals, other molecular cold sensors coexpress with TRPM8, operating in the same temperature range and overlapping in function. Several background $\mathrm{K}^{+}$channels are extremely temperature sensitive, are functional in the same temperature range, and are expressed in sensory neurons, making them obvious candidates to function as additional cold sensors (Maingret et al., 2000; Reid and Flonta, 2001; Viana et al., 2002; Kang et al., 2005).

We consider an alternative explanation for the low sensitivity of cold-sensitive corneal terminals to the blocking actions of BCTC and SKF96365. Native TRPM8 channels in the terminal may occur in a molecular configuration that renders them highly temperature sensitive but resistant to pharmacological blockade. The existence of splice variants with different functional properties has already been reported for other thermoTRP channels in trigeminal neurons (Lu et al., 2005). These alternative explanations can only be addressed with other experimental paradigms, such as the analysis of TRPM8 knock-out mice, specially those lines with spatially restricted and/or temporally conditioned gene inactivation. According to our first hypothesis (coexpression of molecular cold sensors), these animals would show functional deficits in peripheral cold sensing much milder than predicted from results derived from cultured cells, whereas the alternative hypothesis predicts a full inhibition at terminals as well.

\section{Role of TRPM8 channels in cold transduction}

We find that TRPM8 is expressed in CS neurons across the entire spectrum of temperature thresholds, including those into the noxious range. The low-threshold neurons were less likely to be silenced by BCTC, suggesting the presence of an additional population of temperature-sensitive channels in the soma of these neurons. The expression of TRPM8 channels in higher-threshold neurons is consistent with several psychophysical studies suggesting that TRPM8 channels may play a role in human cold nociception. Thus, acute application of menthol to the skin or mucosae can produce a painful sensation in addition to a cold sensation (Cliff and Green, 1994; Acosta et al., 2001; Wasner et al., 2004; Namer et al., 2005). In addition, a large percentage of sensory neurons have a dual response to TRPV1 and TRPM8 agonists (McKemy et al., 2002; Reid et al., 2002; Viana et al., 2002; Xing et al., 2006).

In summary, our results show that the peripheral receptor endings of CS neurons contain TRPM8 channels but that inhibition of these channels does not impair significantly their capacity to transduce or encode cold stimuli. A similar paradox between effects of ion-channel disruption at the level of soma and terminals for temperature sensitivity is also apparent for another thermoTRP. In studies with TRPV1 null mice, deficits in heat sensitivity are only apparent in the soma of cultured sensory neurons (Caterina et al., 2000; Davis et al., 2000), in contrast to the persistence of normal heat responses in afferent C-fibers in skinnerve preparations (Woodbury et al., 2004; Zimmermann et al., 2005), and the lack of differences in behavioral tests of acute thermal nociception between wild-type and TRPV $1^{-/-}$animals (Caterina et al., 2000; Davis et al., 2000; Almasi et al., 2003).

As pointed out by Gerald Edelman, "multiple genes contribute in an overlapping manner to the construction of each phenotypic feature undergoing selection" (Edelman and Gally, 2001). Thermal sensing is a conserved attribute of all animal species, playing an essential role in their behavior, and must be under strong evolutionary pressure. Thus, from an evolutionary perspective, it is understandable and meaningful to have an overlapping functional role of various thermosensitive channels in individual peripheral thermoreceptors as suggested by our findings.

\section{References}

Acosta MC, Belmonte C, Gallar J (2001) Sensory experiences in humans and single-unit activity in cats evoked by polymodal stimulation of the cornea. J Physiol (Lond) 534:511-525.

Almasi R, Petho G, Bolcskei K, Szolcsanyi J (2003) Effect of resiniferatoxin on the noxious heat threshold temperature in the rat: a novel heat allodynia model sensitive to analgesics. Br J Pharmacol 139:49-58.

Babes A, Zorzon D, Reid G (2004) Two populations of cold-sensitive neurons in rat dorsal root ganglia and their modulation by nerve growth factor. Eur J Neurosci 20:2276-2282.

Bandell M, Story GM, Hwang SW, Viswanath V, Eid SR, Petrus MJ, Earley TJ, Patapoutian A (2004) Noxious cold ion channel TRPA1 is activated by pungent compounds and bradykinin. Neuron 41:849-857.

Behrendt HJ, Germann T, Gillen C, Hatt H, Jostock R (2004) Characterization of the mouse cold-menthol receptor TRPM8 and vanilloid receptor type-1 VR1 using a fluorometric imaging plate reader (FLIPR) assay. Br J Pharmacol 141:737-745.

Brauchi S, Orio P, Latorre R (2004) Clues to understanding cold sensation: thermodynamics and electrophysiological analysis of the cold receptor TRPM8. Proc Natl Acad Sci USA 101:15494-15499.

Braun HA, Bade H, Hensel H (1980) Static and dynamic discharge patterns of bursting cold fibers related to hypothetical receptor mechanisms. Pflügers Arch 386:1-9.

Brock J, Pianova S, Belmonte C (2001) Differences between nerve terminal impulses of polymodal nociceptors and cold sensory receptors of the guinea-pig cornea. J Physiol (Lond) 533:493-501.

Brock JA, McLachlan EM, Belmonte C (1998) Tetrodotoxin-resistant impulses in single nociceptor nerve terminals in guinea-pig cornea. J Physiol 512:211-217.

Cabanes C, Viana F, Belmonte C (2003) Differential thermosensitivity of sensory neurons in the guinea pig trigeminal ganglion. J Neurophysiol 90:2219-2231.

Carr RW, Pianova S, Fernandez J, Fallon JB, Belmonte C, Brock JA (2003) Effects of heating and cooling on nerve terminal impulses recorded from coldsensitive receptors in the guinea-pig cornea. J Gen Physiol 121:427-439.

Caterina MJ, Schumacher MA, Tominaga M, Rosen TA, Levine JD, Julius D (1997) The capsaicin receptor: a heat-activated ion channel in the pain pathway. Nature 389:816-824.

Caterina MJ, Leffler A, Malmberg AB, Martin WJ, Trafton J, Petersen-Zeitz KR, Koltzenburg M, Basbaum AI, Julius D (2000) Impaired nociception and pain sensation in mice lacking the capsaicin receptor. Science 288:306-313.

Chen CC, Rainville P, Bushnell MC (1996) Noxious and innocuous cold discrimination in humans: evidence for separate afferent channels. Pain 68:33-43

Clapham DE, Julius D, Montell C, Schultz G (2005) International Union of 
Pharmacology. XLIX. Nomenclature and structure-function relationships of transient receptor potential channels. Pharmacol Rev 57:427-450.

Cliff MA, Green BG (1994) Sensory irritation and coolness produced by menthol: evidence for selective desensitization of irritation. Physiol Behav 56:1021-1029.

Craig AD, Chen K, Bandy D, Reiman EM (2000) Thermosensory activation of insular cortex. Nat Neurosci 3:184-190.

Davis JB, Gray J, Gunthorpe MJ, Hatcher JP, Davey PT, Overend P, Harries MH, Latcham J, Clapham C, Atkinson K, Hughes SA, Rance K, Grau E, Harper AJ, Pugh PL, Rogers DC, Bingham S, Randall A, Sheardown SA (2000) Vanilloid receptor-1 is essential for inflammatory thermal hyperalgesia. Nature 405:183-187.

de la Pena E, Malkia A, Cabedo H, Belmonte C, Viana F (2005) The contribution of TRPM8 channels to cold sensing in mammalian neurones. J Physiol (Lond) 567:415-426.

Edelman GM, Gally JA (2001) Degeneracy and complexity in biological systems. Proc Natl Acad Sci USA 98:13763-13768.

Gallar J, Pozo MA, Tuckett RP, Belmonte C (1993) Response of sensory units with unmyelinated fibres to mechanical, thermal and chemical stimulation of the cat's cornea. J Physiol (Lond) 468:609-622.

Hensel H (1981) Thermoreception and temperature regulation. Monogr Physiol Soc 38:1-321.

Hensel H, Wurster RD (1970) Static properties of cold receptors in nasal area of cats. J Neurophysiol 33:271-275.

Hensel H, Zotterman Y (1951) The response of the cold receptors to constant cooling. Acta Physiol Scand 22:96-113.

Heppelmann B, Messlinger K, Neiss WF, Schmidt RF (1990) Ultrastructural three-dimensional reconstruction of group III and group IV sensory nerve endings ("free nerve endings") in the knee joint capsule of the cat: evidence for multiple receptive sites. J Comp Neurol 292:103-116.

Hill K, McNulty S, Randall AD (2004) Inhibition of TRPM2 channels by the antifungal agents clotrimazole and econazole. Naunyn Schmiedebergs Arch Pharmacol 370:227-237.

Hille B (2001) Ion channels of excitable membranes. Sunderland, MA: Sinauer.

Jordt SE, McKemy DD, Julius D (2003) Lessons from peppers and peppermint: the molecular logic of thermosensation. Curr Opin Neurobiol 13:487-492.

Jordt SE, Bautista DM, Chuang HH, McKemy DD, Zygmunt PM, Hogestatt ED, Meng ID, Julius D (2004) Mustard oils and cannabinoids excite sensory nerve fibres through the TRP channel ANKTM1. Nature 427:260-265.

Kang D, Choe C, Kim D (2005) Thermosensitivity of the two-pore domain $\mathrm{K}^{+}$channels TREK-2 and TRAAK. J Physiol (Lond) 564:103-116.

LaMotte RH, Thalhammer JG (1982) Response properties of high-threshold cutaneous cold receptors in the primate. Brain Res 244:279-287.

Liu BY, Qin F (2005) Functional control of cold- and menthol-sensitive TRPM8 ion channels by phosphatidylinositol 4,5-bisphosphate. J Neurosci $25: 1674-1681$.

Lu G, Henderson D, Liu L, Reinhart PH, Simon SA (2005) TRPV1b, a functional human vanilloid receptor splice variant. Mol Pharmacol 67:1119-1127.

Maingret F, Lauritzen I, Patel AJ, Heurteaux C, Reyes R, Lesage F, Lazdunski M, Honore E (2000) TREK-1 is a heat-activated background $\mathrm{K}^{+}$channel. EMBO J 19:2483-2491.

McKemy DD (2005) How cold is it? TRPM8 and TRPAl in the molecular logic of cold sensation. Mol Pain 1:16.

McKemy DD, Neuhausser WM, Julius D (2002) Identification of a cold receptor reveals a general role for TRP channels in thermosensation. Nature 416:52-58.

Namer B, Seifert F, Handwerker HO, Maihofner C (2005) TRPAl and TRPM8 activation in humans: effects of cinnamaldehyde and menthol. NeuroReport 16:955-959.

Nealen ML, Gold MS, Thut PD, Caterina MJ (2003) TRPM8 mRNA is expressed in a subset of cold-responsive trigeminal neurons from rat. J Neurophysiol 90:515-520.

Nilius B, Prenen J, Vennekens R, Hoenderop JG, Bindels RJ, Droogmans G (2001) Pharmacological modulation of monovalent cation currents through the epithelial $\mathrm{Ca}^{2+}$ channel ECaC1. Br J Pharmacol 134:453-462.

Okazawa M, Takao K, Hori A, Shiraki T, Matsumura K, Kobayashi S (2002) Ionic basis of cold receptors acting as thermostats. J Neurosci 22:3994-4001.

Patapoutian A, Peier AM, Story GM, Viswanath V (2003) ThermoTRP channels and beyond: mechanisms of temperature sensation. Nat Rev Neurosci 4:529-539.

Peier AM, Moqrich A, Hergarden AC, Reeve AJ, Andersson DA, Story GM, Earley TJ, Dragoni I, McIntyre P, Bevan S, Patapoutian A (2002) A TRP channel that senses cold stimuli and menthol. Cell 108:705-715.

Premkumar LS, Raisinghani M, Pingle SC, Long C, Pimentel F (2005) Downregulation of transient receptor potential melastatin 8 by protein kinase C-mediated dephosphorylation. J Neurosci 25:11322-11329.

Reid G (2005) ThermoTRP channels and cold sensing: what are they really up to? Pflügers Arch 451:250-263.

Reid G, Flonta M (2001) Cold transduction by inhibition of a background potassium conductance in rat primary sensory neurones. Neurosci Lett 297:171-174.

Reid G, Amuzescu B, Zech E, Flonta M (2001) A system for applying rapid warming or cooling stimuli to cells during patch clamp recording or ion imaging. J Neurosci Methods 111:1-8.

Reid G, Babes A, Pluteanu F (2002) A cold- and menthol-activated current in rat dorsal root ganglion neurones: properties and role in cold transduction. J Physiol (Lond) 545:595-614.

Rohacs T, Lopes CM, Michailidis I, Logothetis DE (2005) PI(4,5)P2 regulates the activation and desensitization of TRPM8 channels through the TRP domain. Nat Neurosci 8:626-634.

Roza C, Belmonte C, Viana F (2006) Cold sensitivity in axotomized fibers of experimental neuromas in mice. Pain 120:24-35.

Schafer K, Braun HA, Kurten L (1988) Analysis of cold and warm receptor activity in vampire bats and mice. Pflügers Arch 412:188-194.

Simone DA, Kajander KC (1997) Responses of cutaneous A-fiber nociceptors to noxious cold. J Neurophysiol 77:2049-2060.

Story GM, Peier AM, Reeve AJ, Eid SR, Mosbacher J, Hricik TR, Earley TJ, Hergarden AC, Andersson DA, Hwang SW, McIntyre P, Jegla T, Bevan S, Patapoutian A (2003) ANKTM1, a TRP-like channel expressed in nociceptive neurons, is activated by cold temperatures. Cell 112:819-829.

Thut PD, Wrigley D, Gold MS (2003) Cold transduction in rat trigeminal ganglia neurons in vitro. Neuroscience 119:1071-1083.

Valenzano KJ, Grant ER, Wu G, Hachicha M, Schmid L, Tafesse L, Sun Q, Rotshteyn Y, Francis J, Limberis J, Malik S, Whittemore ER, Hodges D (2003) N-(4-tertiarybutylphenyl)-4-(3-chloropyridin-2-yl)tetrahy dropyrazine $-1(2 H)$-carbox-amide (BCTC), a novel, orally effective vanilloid receptor 1 antagonist with analgesic properties. I. in vitro characterization and pharmacokinetic properties. J Pharmacol Exp Ther 306:377-386.

Viana F, de la Pena E, Belmonte C (2002) Specificity of cold thermotransduction is determined by differential ionic channel expression. Nat Neurosci 5:254-260.

Viana F, de la Pena E, Pecson B, Schmidt RF, Belmonte C (2001) Swellingactivated calcium signalling in cultured mouse primary sensory neurons. Eur J Neurosci 13:722-734.

Voets T, Droogmans G, Wissenbach U, Janssens A, Flockerzi V, Nilius B (2004) The principle of temperature-dependent gating in cold- and heatsensitive TRP channels. Nature 430:748-754.

Wang GX, Poo MM (2005) Requirement of TRPC channels in netrin-1induced chemotropic turning of nerve growth cones. Nature 434:898-904.

Wasner G, Schattschneider J, Binder A, Baron R (2004) Topical menthol-a human model for cold pain by activation and sensitization of $\mathrm{C}$ nociceptors. Brain 127:1159-1171.

Weil A, Moore SE, Waite NJ, Randall A, Gunthorpe MJ (2005) Conservation of functional and pharmacological properties in the distantly related temperature sensors TRPV1 and TRPM8. Mol Pharmacol 68:518-527.

Woodbury CJ, Zwick M, Wang S, Lawson JJ, Caterina MJ, Koltzenburg M, Albers KM, Koerber HR, Davis BM (2004) Nociceptors lacking TRPV1 and TRPV2 have normal heat responses. J Neurosci 24:6410-6415.

Xing H, Ling J, Chen M, Gu JG (2006) Chemical and cold sensitivity of two distinct populations of TRPM8-expressing somatosensory neurons. J Neurophysiol 95:1221-1230.

Yarnitsky D, Ochoa JL (1991) Warm and cold specific somatosensory systems. Psychophysical thresholds, reaction times and peripheral conduction velocities. Brain 114:1819-1826.

Zimmermann K, Leffler A, Fischer MM, Messlinger K, Nau C, Reeh PW (2005) The TRPV1/2/3 activator 2-aminoethoxydiphenyl borate sensitizes native nociceptive neurons to heat in wildtype but not TRPV1 deficient mice. Neuroscience 135:1277-1284. 